Cochrane Database of Systematic Reviews

\title{
Botulinum toxin for the treatment of strabismus (Review)
}

Rowe FJ, Noonan CP

Rowe FJ, Noonan CP.

Botulinum toxin for the treatment of strabismus.

Cochrane Database of Systematic Reviews 2017, Issue 3. Art. No.: CD006499.

DOI: 10.1002/14651858.CD006499.pub4.

www.cochranelibrary.com 
TABLE OF CONTENTS

ABSTRACT

PLAIN LANGUAGE SUMMARY

SUMMARY OF FINDINGS

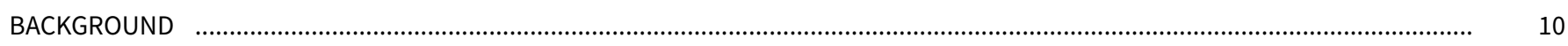

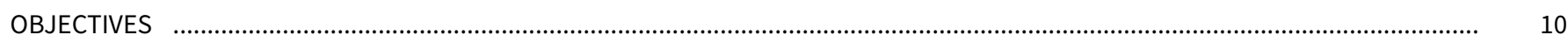

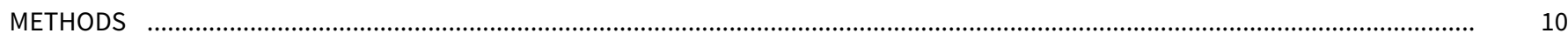

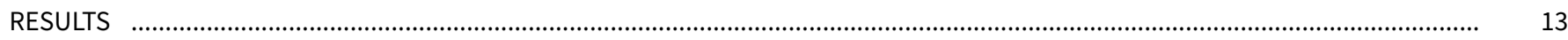

Figure 1.

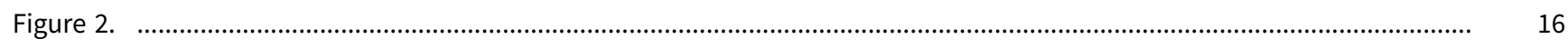

Figure 3.

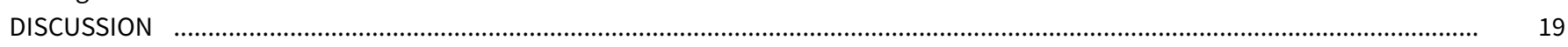

AUTHORS' CONCLUSIONS

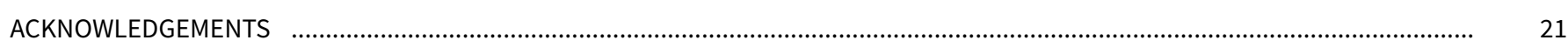

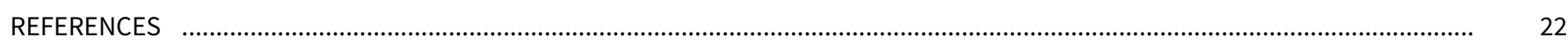

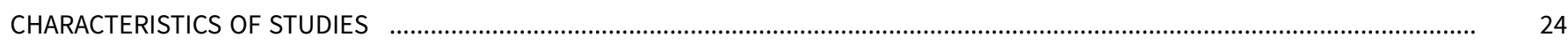

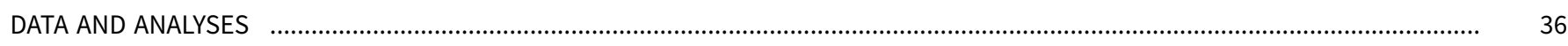

Analysis 1.1. Comparison 1 Botulinum toxin versus surgery, Outcome 1 Primary outcome -improved ocular alignment $\leq 10$ PD. 37

Analysis 1.2. Comparison 1 Botulinum toxin versus surgery, Outcome 2 Secondary outcome - achievement of binocular single 37 vision.

Analysis 1.3. Comparison 1 Botulinum toxin versus surgery, Outcome 3 Secondary outcome - achievement of 'sensory' fusion. 37

Analysis 1.4. Comparison 1 Botulinum toxin versus surgery, Outcome 4 Secondary outcome - achievement of stereopsis. ....... 38

Analysis 2.1. Comparison 2 Botulinum toxin versus observation, Outcome 1 Primary outcome - improvement of ocular 38 alignment $\leq 10 \mathrm{PD}$.

Analysis 2.2. Comparison 2 Botulinum toxin versus observation, Outcome 2 Secondary outcome - classification. .................... 38

Analysis 2.3. Comparison 2 Botulinum toxin versus observation, Outcome 3 Secondary outcome - achievement of binocular 39 single vision.

Analysis 3.1. Comparison 3 Surgery with botulinum toxin versus surgery without botulinum toxin, Outcome 1 Primary outcome - improved ocular alignment $\leq 10$ PD.

Analysis 4.1. Comparison 4 Botulinum toxin with sodium hyaluronate versus botulinum toxin without sodium hyaluronate, Outcome 1 Primary outcome - improved ocular alignment $\leq 10$ PD.

ADDITIONAL TABLES

APPENDICES

WHAT'S NEW

HISTORY

CONTRIBUTIONS OF AUTHORS

DECLARATIONS OF INTEREST

SOURCES OF SUPPORT

DIFFERENCES BETWEEN PROTOCOL AND REVIEW

INDEX TERMS

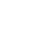

4

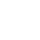

10

(4)

6

17

1

1

2

4

37


[Intervention Review]

\section{Botulinum toxin for the treatment of strabismus}

Fiona J Rowe ${ }^{1}$, Carmel P Noonan²

1Department of Health Services Research, University of Liverpool, Liverpool, UK. 2Department of Ophthalmology, Aintree University Hospitals NHS Foundation Trust, Liverpool, UK

Contact: Fiona J Rowe, Department of Health Services Research, University of Liverpool, Waterhouse Building (B211), 1-3 Brownlow Street, Liverpool, L69 3GL, UK. rowef@liverpool.ac.uk.

Editorial group: Cochrane Eyes and Vision Group.

Publication status and date: New search for studies and content updated (no change to conclusions), published in Issue 3, 2017.

Citation: Rowe FJ, Noonan CP. Botulinum toxin for the treatment of strabismus. Cochrane Database of Systematic Reviews 2017 , Issue 3. Art. No.: CD006499. DOI: 10.1002/14651858.CD006499.pub4.

Copyright (c) 2017 The Cochrane Collaboration. Published by John Wiley \& Sons, Ltd.

\section{A B S T R A C T}

\section{Background}

The use of botulinum toxin as an investigative and treatment modality for strabismus is well reported in the medical literature. However, it is unclear how effective it is in comparison to other treatment options for strabismus.

\section{Objectives}

The primary objective was to examine the efficacy of botulinum toxin therapy in the treatment of strabismus compared with alternative conservative or surgical treatment options. This review sought to ascertain those types of strabismus that particularly benefit from the use of botulinum toxin as a treatment option (such as small angle strabismus or strabismus with binocular potential, i.e. the potential to use both eyes together as a pair). The secondary objectives were to investigate the dose effect and complication rates associated with botulinum toxin.

\section{Search methods}

We searched CENTRAL (which contains the Cochrane Eyes and Vision Trials Register) (2016, Issue 6), Ovid MEDLINE, Ovid MEDLINE InProcess and Other Non-Indexed Citations, Ovid MEDLINE Daily, Ovid OLDMEDLINE (January 1946 to July 2016), Embase (January 1980 to July 2016), Latin American and Caribbean Literature on Health Sciences (LILACS) (January 1982 to July 2016), the ISRCTN registry (www.isrctn.com/editAdvancedSearch), ClinicalTrials.gov (www.clinicaltrials.gov), and the World Health Organization (WHO) International Clinical Trials Registry Platform (ICTRP) (www.who.int/ictrp/search/en). We did not use any date or language restrictions in the electronic searches for trials. We last searched the electronic databases on 11 July 2016. We handsearched the British and Irish Orthoptic Journal, Australian Orthoptic Journal, proceedings of the European Strabismological Association (ESA), International Strabismological Association (ISA) and International Orthoptic Association (IOA) (www.liv.ac.uk/orthoptics/research/search.htm) and American Academy of Paediatric Ophthalmology and Strabismus meetings (AAPOS). We contacted researchers who are active in this field for information about further published or unpublished studies.

\section{Selection criteria}

We included randomised controlled trials (RCTS) of any use of botulinum toxin treatment for strabismus.

\section{Data collection and analysis}

Two review authors independently selected studies and extracted data. We used standard methods expected by Cochrane and assessed the certainty of the evidence using GRADE. We defined ocular alignment as an angle of deviation of less than or equal to 10 prism dioptres. 


\section{Main results}

Six RCTs were eligible for inclusion. We judged the included studies as at a mixture of low, unclear and high risk of bias. We did not consider any of the included studies as at low risk of bias for all domains.

Two trials conducted in Spain (102 people, number of eyes not specified) compared botulinum toxin with surgery in children that required retreatment for acquired or infantile esotropia. These two studies provided low-certainty evidence that children who received botulinum toxin may have a similar or slightly reduced chance of achieving ocular alignment (pooled risk ratio (RR) $0.91,95 \%$ confidence interval (CI) 0.71 to 1.16 ), binocular single vision ( $R R 0.88,95 \% \mathrm{Cl} 0.63$ to 1.23 ), sensory fusion (RR $0.88,95 \% \mathrm{Cl} 0.63$ to 1.23 ) and stereopsis (RR 0.86 , $95 \% \mathrm{Cl} 0.59$ to 1.25 ) compared with children who received surgery. One trial from Canada compared botulinum toxin with surgery in 30 adults (30 eyes) with horizontal strabismus and reported a reduced chance of ocular alignment with botulinum toxin ( $\mathrm{RR} 0.38,95 \% \mathrm{Cl} 0.17$ to 0.85 ; low-certainty evidence).

One trial in the UK suggested that botulinum toxin may result in a similar or slightly improved chance of ocular alignment in people with acute onset sixth nerve palsy compared with observation (RR 1.19, 95\% Cl 0.96 to 1.48; 47 participants, low-certainty evidence).

Very low-certainty evidence from one trial from Brazil suggested that adjuvant botulinum toxin in strabismus surgery may increase the chances of ocular alignment compared with strabismus surgery alone (RR $1.83,95 \% \mathrm{Cl} 0.41$ to $8.11 ; 23$ participants).

One trial from China of 47 participants (94 eyes) suggested that people receiving botulinum toxin combined with sodium hyaluronate may have a similar or slightly reduced chance of achieving ocular alignment compared with botulinum toxin alone (RR $0.81,95 \% \mathrm{Cl} 0.36$ to 1.82 ; low-certainty evidence).

Reported complications in people given botulinum toxin in the included trials included ptosis (range $9 \%$ to $41.66 \%$ ) and vertical deviation (range $8.3 \%$ to $18.51 \%$ ). Ptosis occurred less frequently when treated with botulinum toxin combined with sodium hyaluronate compared to botulinum toxin alone.

\section{Authors' conclusions}

Most published literature on the use of botulinum toxin in the treatment of strabismus consists of retrospective studies, cohort studies or case reviews. Although these provide useful descriptive information, clarification is required as to the effective use of botulinum toxin as an independent treatment modality. Six RCTs on the therapeutic use of botulinum toxin in strabismus, graded as low and very lowcertainty evidence, have shown varying responses. These include a lack of evidence for effect of botulinum toxin on reducing visual symptoms in acute sixth nerve palsy, poor response in people with horizontal strabismus without binocular vision, similar or slightly reduced achievement of successful ocular alignment in children with esotropia and potential increased achievement of successful ocular alignment where surgery and botulinum toxin are combined. Further high quality trials using robust methodologies are required to compare the clinical and cost effectiveness of various forms of botulinum toxin (e.g. Dysport, Xeomin, etc), to compare botulinum toxin with and without adjuvant solutions and to compare botulinum toxin to alternative surgical interventions in strabismus cases with and without potential for binocular vision.

\section{PLAIN LANGUAGE SUMMARY}

\section{Botulinum toxin for the treatment of strabismus}

\section{What is the aim of this review?}

The aim of this Cochrane Review was to find out how well botulinum toxin works as a treatment for strabismus. Cochrane researchers collected and analysed all relevant studies to answer this question and included six studies.

\section{Key messages}

The evidence as to the benefits and harms of using botulinum toxin for strabismus is uncertain.

\section{What was studied in the review?}

Strabismus occurs when the eyes are not aligned. Usually one eye turns inwards or outwards. Less frequently one eye turns upwards or downwards. It is commonly known as "squint".

Strabismus can lead to blurred vision or double vision. In children it can affect the long term development of vision in the affected eye. There are many causes of strabismus. In most cases, there are problems with the muscles or nerves around the eye.

Doctors can use botulinum toxin to stop individual muscles around the eye working for a while. This may help the eyes become more aligned and may lead to less blurred or double vision. One problem with using botulinum toxin is that it can result in a droopy eyelid (ptosis).

\section{What are the main results of the review?}

The review shows that:

- using botulinum toxin in children requiring primary treatment or retreatment for strabismus may make no difference, or slightly reduce the chances of recovering correct alignment of the eyes compared with surgery (low-certainty evidence); 
- using botulinum toxin in adults with strabismus may decrease the chances of recovering correct alignment of the eyes compared with surgery (low-certainty evidence);

- people with sixth nerve palsy receiving botulinum toxin may have a similar or small increased chance of correct alignment of eyes compared with no treatment (low-certainty evidence);

- the evidence on using botulinum toxin with surgery, compared with surgery alone, was very uncertain (very low-certainty evidence);

- ptosis occurred commonly in people receiving botulinum toxin in these studies. The number of people affected ranged from 1 in 10 to

1 in 2 people. Everyone recovered when treatment stopped. Ptosis occurred less frequently when treated with botulinum toxin combined with sodium hyaluronate compared to botulinum toxin alone.

\section{How up-to-date is this review?}

The Cochrane researchers searched for studies that had been published up to 11 July 2016. 


\begin{tabular}{|c|c|c|c|c|c|c|c|}
\hline \multirow{13}{*}{ 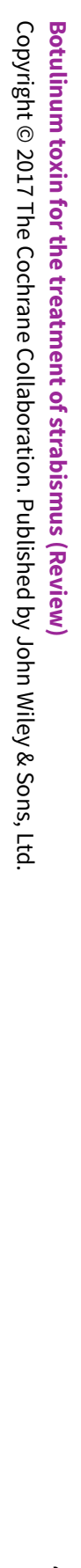 } & \multicolumn{7}{|c|}{\begin{tabular}{|l} 
S U M M A R Y O F F I N D I N G S \\
Summary of findings for the main comparison. Botulinum toxin versus surgery
\end{tabular}} \\
\hline & \multicolumn{7}{|c|}{ Botulinum toxin versus surgery in adults and children with strabismus } \\
\hline & \multicolumn{7}{|c|}{$\begin{array}{l}\text { Patient or population: adults and children with strabismus } \\
\text { Setting: hospital } \\
\text { Intervention: botulinum toxin } \\
\text { Comparison: surgery }\end{array}$} \\
\hline & \multirow[t]{2}{*}{ Outcomes } & \multicolumn{2}{|c|}{ Anticipated absolute effects ${ }^{\star}(95 \% \mathrm{CI})$} & \multirow{2}{*}{$\begin{array}{l}\text { Relative effect } \\
(95 \% \mathrm{Cl})\end{array}$} & \multirow{2}{*}{$\begin{array}{l}\text { Number of par- } \\
\text { ticipants } \\
\text { (studies) }\end{array}$} & \multirow{2}{*}{$\begin{array}{l}\text { Certainty of } \\
\text { the evidence } \\
\text { (GRADE) }\end{array}$} & \multirow[t]{2}{*}{ Comments } \\
\hline & & $\begin{array}{l}\text { Risk with } \\
\text { surgery }\end{array}$ & $\begin{array}{l}\text { Risk with botulinum } \\
\text { toxin }\end{array}$ & & & & \\
\hline & \multirow{4}{*}{$\begin{array}{l}\text { Primary outcome: im- } \\
\text { proved ocular alignment } \\
\leq 10 \text { PD } \\
\text { Follow-up: median } 6 \\
\text { months }\end{array}$} & \multicolumn{6}{|l|}{ Children } \\
\hline & & 750 per 1000 & $\begin{array}{l}683 \text { per } 1000 \\
(533 \text { to } 870)\end{array}$ & $\begin{array}{l}\text { RR } 0.91,(0.71 \text { to } \\
1.16)\end{array}$ & $\begin{array}{l}102 \\
\text { (2 RCTs) }\end{array}$ & $\begin{array}{l}\oplus \oplus \oplus \ominus \\
\text { low } 1,2\end{array}$ & $\begin{array}{l}\text { Downgraded } 1 \text { level for risk of bias. } \\
\text { Downgraded } 1 \text { level for imprecision. }\end{array}$ \\
\hline & & \multicolumn{6}{|l|}{ Adults } \\
\hline & & 750 per 1000 & $\begin{array}{l}285 \text { per } 1000 \text { (128 to } \\
638)\end{array}$ & $\begin{array}{l}\text { RR } 0.38(0.17 \text { to } \\
0.85)\end{array}$ & $\begin{array}{l}30 \\
(1 \mathrm{RCT})\end{array}$ & $\begin{array}{l}\oplus \oplus \ominus \ominus \\
\text { low } 1,2\end{array}$ & $\begin{array}{l}\text { Downgraded } 1 \text { level for risk of bias. } \\
\text { Downgraded } 1 \text { level for imprecision. }\end{array}$ \\
\hline & $\begin{array}{l}\text { Secondary outcome: } \\
\text { achievement of binocu- } \\
\text { lar single vision }\end{array}$ & 616 per 1000 & $\begin{array}{l}542 \text { per } 1000 \\
(388 \text { to } 758)\end{array}$ & $\begin{array}{l}\text { RR } 0.88 \\
(0.63 \text { to } 1.23)\end{array}$ & $\begin{array}{l}102 \\
(2 \text { RCTs })\end{array}$ & $\begin{array}{l}\oplus \oplus \oplus \ominus \\
\operatorname{low}^{1,2}\end{array}$ & $\begin{array}{l}\text { Downgraded } 1 \text { level for risk of bias. } \\
\text { Downgraded } 1 \text { level for imprecision. }\end{array}$ \\
\hline & $\begin{array}{l}\text { Secondary outcome: } \\
\text { achievement of 'senso- } \\
\text { ry' fusion }\end{array}$ & 616 per 1000 & $\begin{array}{l}542 \text { per } 1000 \\
\text { (388 to } 758)\end{array}$ & $\begin{array}{l}\text { RR } 0.88 \\
\text { (0.63 to } 1.23 \text { ) }\end{array}$ & $\begin{array}{l}102 \\
\text { (2 RCTs) }\end{array}$ & $\begin{array}{l}\oplus \oplus \oplus \ominus \\
\text { low } 1,2\end{array}$ & $\begin{array}{l}\text { Downgraded } 1 \text { level for risk of bias. } \\
\text { Downgraded } 1 \text { level for imprecision. }\end{array}$ \\
\hline & $\begin{array}{l}\text { Secondary outcome: } \\
\text { achievement of stereop- } \\
\text { sis }\end{array}$ & 557 per 1000 & $\begin{array}{l}479 \text { per } 1000 \\
(328 \text { to } 696)\end{array}$ & $\begin{array}{l}\text { RR } 0.86 \\
(0.59 \text { to } 1.25)\end{array}$ & $\begin{array}{l}102 \\
(2 \text { RCTs })\end{array}$ & $\begin{array}{l}\oplus \oplus \ominus \ominus \\
l_{0} 1,2\end{array}$ & $\begin{array}{l}\text { Downgraded } 1 \text { level for risk of bias. } \\
\text { Downgraded } 1 \text { level for imprecision. }\end{array}$ \\
\hline & $\begin{array}{l}\text { Adverse events with bot- } \\
\text { ulinum toxin } \\
\text { Follow-up: median } 6 \\
\text { months }\end{array}$ & $\begin{array}{l}\text { Induced ptos } \\
\text { across trials. } \\
\text { Induced verti } \\
8.3 \% \text { across t }\end{array}$ & $\begin{array}{l}\text { Irred in } 20.8 \text { to } 41.66 \% \\
\text { jiation occurred in } 2.2 \text { to }\end{array}$ & - & $\begin{array}{l}102 \\
(2 \mathrm{RCTs})\end{array}$ & $\begin{array}{l}\oplus \oplus \oplus \ominus \\
\text { low }^{1,2}\end{array}$ & $\begin{array}{l}\text { Downgraded } 1 \text { level for risk of bias. } \\
\text { Downgraded } 1 \text { level for imprecision. }\end{array}$ \\
\hline
\end{tabular}


${ }^{*}$ The risk in the intervention group (and its $95 \% \mathrm{Cl}$ ) is based on the assumed risk in the comparison group and the relative effect of the intervention (and its $95 \% \mathrm{Cl}$ ). We derived the relative risk from the standardised mean difference for continuous data related to measured change in angle of deviation, measured in prism dioptres (PD) or degrees. Relative risk for dichotomous data relating to achievement of binocular single vision as assessed by cover test, fusional vergence and stereoacuity.

Abbreviations: Cl: confidence interval; RR: risk ratio; OR: odds ratio; PD: prism dioptres; RCT: randomised controlled trial.

\section{GRADE Working Group grades of evidence}

High-certainty: we are very confident that the true effect lies close to that of the estimate of the effect.

Moderate-certainty: we are moderately confident in the effect estimate. The true effect is likely to be close to the estimate of the effect, but there is a possibility that it is substantially different.

Low-certainty: our confidence in the effect estimate is limited. The true effect may be substantially different from the estimate of the effect.

Very low-certainty: we have very little confidence in the effect estimate. The true effect is likely to be substantially different from the estimate of effect.

1There was unclear sequence generation for 3 trials; the study investigators were aware of patient randomisation in the Tejedor 1998 and Tejedor 1999 trials.

2It was unclear from the results how many participants received unilateral or bilateral injections of botulinum toxin in the Tejedor 1998 and Tejedor 1999 trials. Bilateral injection would have a greater effect on the angle of deviation than unilateral injection.

\section{Summary of findings 2. Botulinum toxin versus observation}

Botulinum toxin versus observation in adults with strabismus

Patient or population: adults with strabismus due to acute onset sixth nerve palsy

Setting: hospital

Intervention: botulinum toxin

Comparison: observation

\begin{tabular}{|c|c|c|c|c|c|c|}
\hline \multirow[t]{2}{*}{ Outcomes } & \multicolumn{2}{|c|}{ Anticipated absolute effects ${ }^{\star}(95 \% \mathrm{Cl})$} & \multirow{2}{*}{$\begin{array}{l}\text { Relative effect } \\
(95 \% \mathrm{CI})\end{array}$} & \multirow{2}{*}{$\begin{array}{l}\text { Number of par- } \\
\text { ticipants } \\
\text { (studies) }\end{array}$} & \multirow{2}{*}{$\begin{array}{l}\text { Certainty of } \\
\text { the evidence } \\
\text { (GRADE) }\end{array}$} & \multirow[t]{2}{*}{ Comments } \\
\hline & $\begin{array}{l}\text { Risk with } \\
\text { surgery }\end{array}$ & $\begin{array}{l}\text { Risk with botulinum } \\
\text { toxin }\end{array}$ & & & & \\
\hline \multirow{2}{*}{$\begin{array}{l}\text { Primary outcome: improved ocular } \\
\text { alignment } \leq 10 \mathrm{PD} \\
\text { Follow-up: median } 6 \text { months }\end{array}$} & 800 per 1000 & $\begin{array}{l}952 \text { per } 1000 \\
\text { (768 to } 1000)\end{array}$ & $\begin{array}{l}\text { RR } 1.19 \\
\text { (0.96 to } 1.48)\end{array}$ & $\begin{array}{l}47 \\
(1 \mathrm{RCT})\end{array}$ & $\begin{array}{l}\oplus \oplus \ominus \ominus \\
l o w^{1,2}\end{array}$ & $\begin{array}{l}\text { Downgraded } 1 \text { level for } \\
\text { risk of bias. }\end{array}$ \\
\hline & & & & & & $\begin{array}{l}\text { Downgraded } 1 \text { level for } \\
\text { imprecision. }\end{array}$ \\
\hline $\begin{array}{l}\text { Secondary outcome: achievement of } \\
\text { binocular single vision }\end{array}$ & 800 per 1000 & $\begin{array}{l}952 \text { per } 1000 \\
\text { (768 to } 1000)\end{array}$ & $\begin{array}{l}\text { RR } 1.19 \\
\text { (0.96 to } 1.48)\end{array}$ & $\begin{array}{l}47 \\
(1 \mathrm{RCT})\end{array}$ & $\begin{array}{l}\oplus \oplus \ominus \ominus \\
\text { low } 1,2\end{array}$ & $\begin{array}{l}\text { Downgraded } 1 \text { level for } \\
\text { risk of bias. }\end{array}$ \\
\hline
\end{tabular}




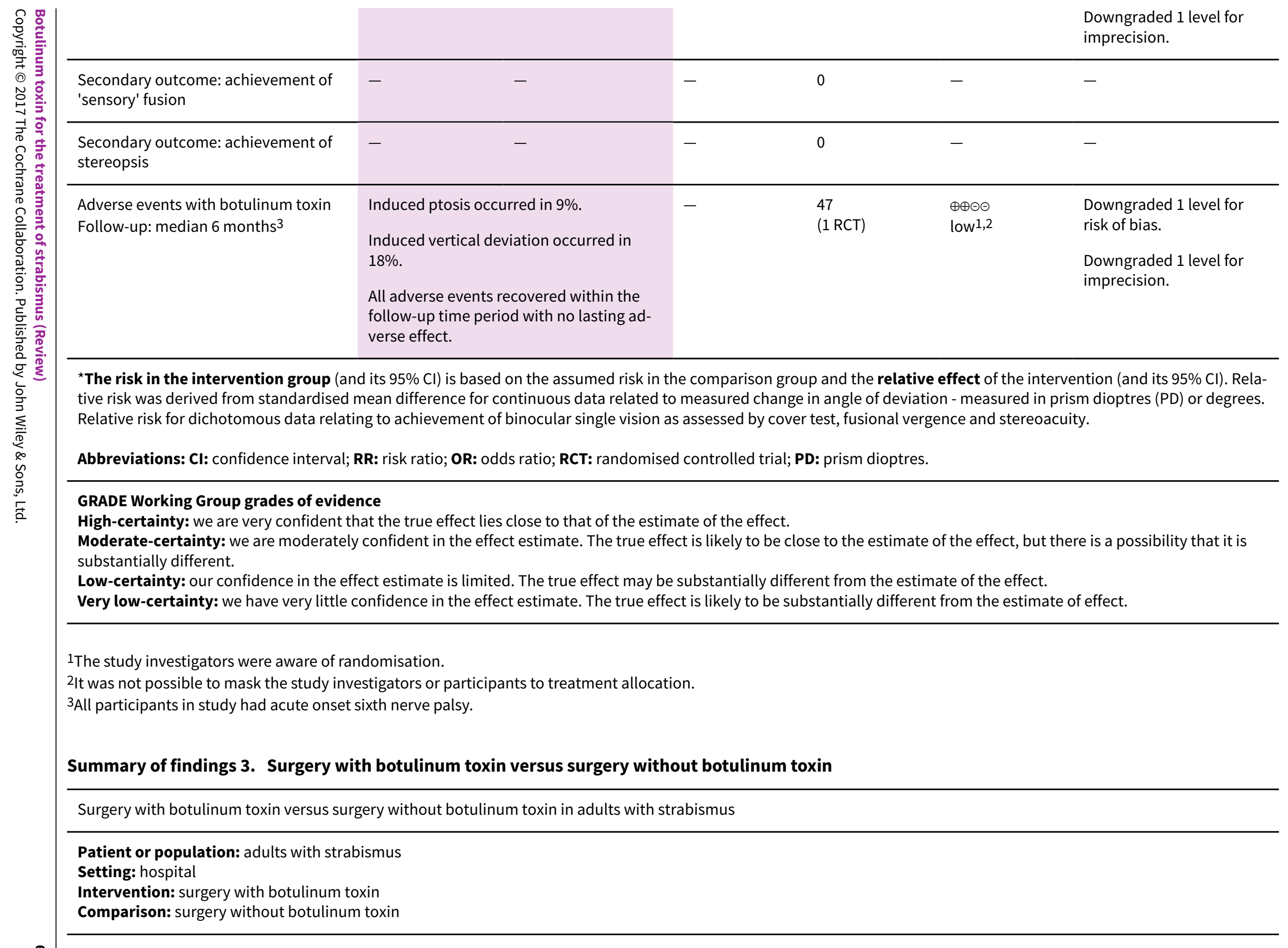




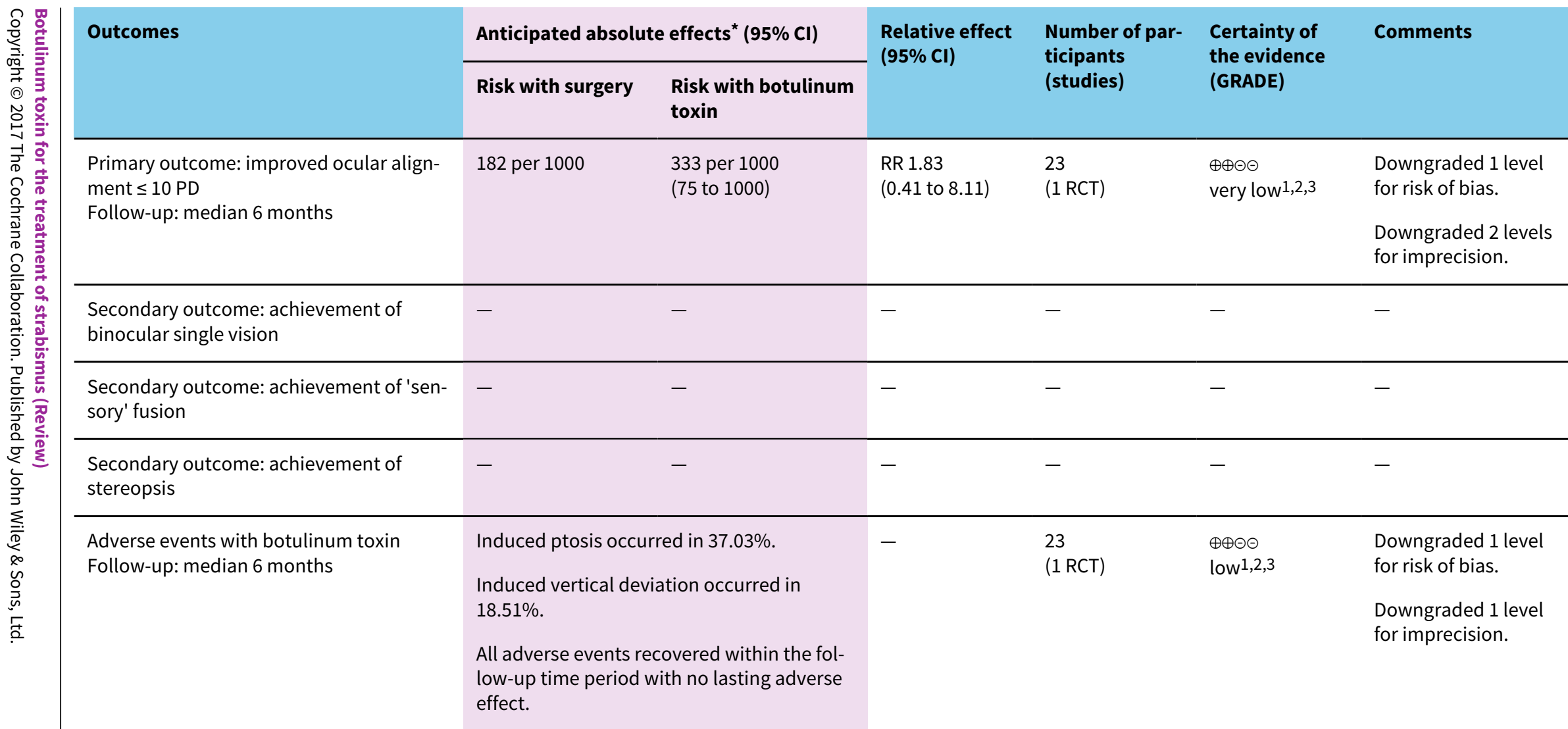

${ }^{\star}$ The risk in the intervention group (and its $95 \% \mathrm{Cl}$ ) is based on the assumed risk in the comparison group and the relative effect of the intervention (and its $95 \% \mathrm{Cl}$ ). We derived the relative risk from the standardised mean difference for continuous data related to measured change in angle of deviation, measured in prism dioptres (PD) or degrees. Relative risk for dichotomous data relating to achievement of binocular single vision was assessed by cover test, fusional vergence and stereoacuity. Abbreviations: Cl: confidence interval; RR: risk ratio; OR: odds ratio; PD: prism dioptres; RCT: randomised controlled trial.

\section{GRADE Working Group grades of evidence}

High-certainty: we are very confident that the true effect lies close to that of the estimate of the effect.

Moderate-certainty: we are moderately confident in the effect estimate. The true effect is likely to be close to the estimate of the effect, but there is a possibility that it is substantially different.

Low-certainty: our confidence in the effect estimate is limited. The true effect may be substantially different from the estimate of the effect.

Very low-certainty: we have very little confidence in the effect estimate. The true effect is likely to be substantially different from the estimate of effect.

1 Unclear if participants blinded to treatment allocation.

2Unclear how the sequence generation was made as it was unspecified.

3 Mixed population of esotropia and exotropia participants, which reduced the numbers of participants for comparison. 
Botulinum toxin with sodium hyaluronate versus botulinum toxin without sodium hyaluronate in children with strabismus

Patient or population: children with strabismus

Setting: hospital

Intervention: botulinum toxin with sodium hyaluronate

Comparison: botulinum toxin without sodium hyaluronate

\begin{tabular}{|c|c|c|c|c|c|c|}
\hline \multirow[t]{2}{*}{ Outcomes } & \multicolumn{2}{|c|}{ Anticipated absolute effects ${ }^{\star}(95 \% \mathrm{CI})$} & \multirow{2}{*}{$\begin{array}{l}\text { Relative effect } \\
(95 \% \mathrm{CI})\end{array}$} & \multirow{2}{*}{$\begin{array}{l}\text { Number of par- } \\
\text { ticipants } \\
\text { (studies) }\end{array}$} & \multirow{2}{*}{$\begin{array}{l}\text { Certainty of } \\
\text { the evidence } \\
\text { (GRADE) }\end{array}$} & \multirow[t]{2}{*}{ Comments } \\
\hline & Risk with surgery & Risk with botulinum toxin & & & & \\
\hline \multirow[t]{2}{*}{$\begin{array}{l}\text { Primary outcome: improved ocu- } \\
\text { lar alignment } \leq 10 \mathrm{PD} \\
\text { Follow-up: median } 6 \text { months }\end{array}$} & 375 per 1000 & $\begin{array}{l}304 \text { per } 1000 \\
\text { (135 to } 683)\end{array}$ & $\begin{array}{l}\text { RR } 0.81 \\
\text { (0.36 to } 1.82)\end{array}$ & $\begin{array}{l}47 \\
(1 \mathrm{RCT})\end{array}$ & $\begin{array}{l}\oplus \oplus \odot \ominus \\
\operatorname{low} 1,2\end{array}$ & $\begin{array}{l}\text { Downgraded } 1 \\
\text { level for risk of } \\
\text { bias. }\end{array}$ \\
\hline & & & & & & $\begin{array}{l}\text { Downgraded } 1 \\
\text { level for impreci- } \\
\text { sion. }\end{array}$ \\
\hline $\begin{array}{l}\text { Secondary outcome: achieve- } \\
\text { ment of binocular single vision }\end{array}$ & - & - & - & - & - & - \\
\hline $\begin{array}{l}\text { Secondary outcome: achieve- } \\
\text { ment of 'sensory' fusion }\end{array}$ & - & - & - & - & - & - \\
\hline $\begin{array}{l}\text { Secondary outcome: achieve- } \\
\text { ment of stereopsis }\end{array}$ & - & - & - & - & - & - \\
\hline \multirow[t]{3}{*}{$\begin{array}{l}\text { Adverse events with botulinum } \\
\text { toxin } \\
\text { Follow-up: median } 6 \text { months }\end{array}$} & \multicolumn{2}{|c|}{$\begin{array}{l}\text { Induced ptosis occurred in } 23.4 \% \text { overall; } 2.2 \% \text { in group } \\
\mathrm{A} \text { and } 20.8 \% \text { in group B. }\end{array}$} & - & $\begin{array}{l}47 \\
(1 \mathrm{RCT})\end{array}$ & $\begin{array}{l}\oplus \oplus \oplus \ominus \\
l o w^{1,2}\end{array}$ & $\begin{array}{l}\text { Downgraded } 1 \\
\text { level for risk of } \\
\text { bias. }\end{array}$ \\
\hline & \multirow{2}{*}{\multicolumn{2}{|c|}{$\begin{array}{l}\text { Ptosis occurred less frequently when treated with bot- } \\
\text { ulinum toxin combined with sodium hyaluronate com- } \\
\text { pared to botulinum toxin alone. } \\
\text { All adverse events recovered within the follow-up time } \\
\text { period with no lasting adverse effect. }\end{array}$}} & & & & $\begin{array}{l}\text { Downgraded } 1 \\
\text { level for impreci- } \\
\text { sion. }\end{array}$ \\
\hline & & & & & & \\
\hline
\end{tabular}

${ }^{*}$ The risk in the intervention group (and its $95 \% \mathrm{Cl}$ ) is based on the assumed risk in the comparison group and the relative effect of the intervention (and its $95 \% \mathrm{Cl}$ ). We derived the relative risk from the standardised mean difference for continuous data related to measured change in angle of deviation, measured in prism dioptres (PD) or degrees. Relative risk for dichotomous data relating to achievement of binocular single vision was assessed by cover test, fusional vergence and stereoacuity. 
GRADE Working Group grades of evidence

High-certainty: we are very confident that the true effect lies close to that of the estimate of the effect.

Moderate-certainty: we are moderately confident in the effect estimate. The true effect is likely to be close to the estimate of the effect, but there is a possibility that it is substantially different.

Low-certainty: our confidence in the effect estimate is limited. The true effect may be substantially different from the estimate of the effect.

Very low-certainty: we have very little confidence in the effect estimate. The true effect is likely to be substantially different from the estimate of effect.

1Sequence generation was not specified for this trial; it was unclear how participants were randomised.

2The study investigators were aware of participation randomisation and were not masked to allocation. 


\section{B A C K G R O U N D}

\section{Description of the condition}

Strabismus is a deviation of the ocular alignment where one eye turns, which may be intermittent or constant. It is a common condition that occurs in up to $5 \%$ of the population and up to $50 \%$ in special populations such as those with cerebral palsy (Adams 2005; Donnelly 2005; Strömland 1993). In forms of strabismus that are intermittent, binocular function (using both eyes as a pair) is maintained with straight eyes for a variable proportion of the time. In other forms there is a manifest deviation usually with a variable degree of suppression of the deviating eye. Strabismus can be further divided into esotropia (inturning deviation), exotropia (out-turning deviation) or, less commonly, hypertropia (upturning deviation), hypotropia (downturning deviation) and cyclotropia (rotatory deviation). Strabismus can be caused by a variety of insults such as abnormal anatomical development of extraocular muscles or the orbit, impaired neurological input to extraocular muscles, uncorrected refractive error or hereditary factors. Sequelae to strabismus can include blurring of vision, diplopia (double vision), impaired depth (3-D) perception, and in younger children, amblyopia. Amblyopia is impaired vision in the deviating eye due to the lack of correct stimulation of that eye and results in permanent loss of vision if left untreated at a young age.

\section{Description of the intervention}

There are various treatments associated with strabismus. Primarily treatment is directed at aligning the visual axes. Conservative options include prisms to realign the visual axes and orthoptic exercises to promote and establish binocular control of ocular alignment where both eyes can subsequently work as a pair. Invasive treatment options include surgery to permanently alter extraocular muscle function and thus permanently change ocular alignment, and botulinum toxin to individual extraocular muscles. Scott 1980 first described this latter option, which temporarily paralyses the extraocular muscle and results in a changed ocular alignment that resolves over time (usually a two to three month time interval). During this period of altered eye position, the visual axes may adopt an ocular alignment that permits binocular single vision. This is the ability to use both eyes as a pair so that both eyes contribute to seeing a single image. This may persist or regress necessitating further treatment. Botulinum toxin injection to extraocular muscles is an alternative option that has become established in the treatment of adults who have strabismus. Its use in children is less well studied. It is perceived to be difficult to use in children due to the need for sedation and complications following leakage of the toxin into the levator palpebral superioris muscle (the muscle responsible for elevating the eyelid) thus resulting in a droopy upper lid, known as ptosis (Rowe 2005).

Botulinum toxin has become recognised and accepted as both an adjunct and alternative to strabismus surgery in many types of strabismus (Bunting 2013; Campos 2000; Crouch 2006; Dawson 1999; Dawson 2004a; Dawson 2004b; Dawson 2005; Dawson 2012; Gardner 2013; Holmes 2001; Kerr 2001; Marsh 2003; McNeer 2003; Ozkan 2006; Rayner 1999; Rowe 2004; Sabetti 2003; Spencer 1997; Tejedor 2001). Diagnostic uses of botulinum toxin include investigation of postoperative diplopia (double vision), to detect whether fusion (which contributes to binocular vision) is present preoperatively, to differentially diagnose between a part and complete sixth nerve palsy, to aid in the prediction of surgical results for incomitant deviations and to help in the investigation of a possible slipped muscle following surgery. In terms of therapeutic uses botulinum toxin has been found useful in treating facial muscle spasm, strabismus, nystagmus, corneal ulceration and exposure keratitis to name a few. The therapeutic uses of botulinum toxin for strabismus are to restore fusion in those people with decompensating deviations, or those with a recovering sixth nerve palsy, to align the cosmetic form of strabismus, to aid surgical overcorrections and undercorrections and to aid in the improvement of visual acuity by relieving oscillopsia (perception of moving images) in cases of acquired nystagmus.

Other treatment options associated with strabismus include those that address the sequelae of strabismus, such as occlusion therapy for amblyopia which is a reduction in vision caused completely or in part by the strabismus.

\section{How the intervention might work}

Botulinum toxin is a drug that is an exotoxin of the bacterium Clostridium botulinum. Botulinum toxin type $A$ is an injectable neurotoxin. In order for muscles to contract, acetylcholine is released at the nerve-muscle junction. Acetylcholine binds to muscle receptors causing a contraction. Botulinum toxin selectively blocks the release of acetylcholine from the cholinergic synapses found within a muscle, thereby blocking the nerve impulses and preventing contraction of the muscle cells. Paralysis (which is temporary) follows within days after injection of the toxin into the extraocular muscle, and the toxin becomes fully effective within three to seven days of the injection. The duration of paralysis is dependent on the individual, but generally lasts for three months. Once a muscle is paralysed, opposing muscles take on a greater movement force and the eye position changes allowing the visual axes to move into a straighter eye alignment.

\section{Why it is important to do this review}

Clear guidelines do not exist as to the recommended use of botulinum toxin for the treatment of strabismus particularly as so many types of strabismus exist. Much of the published literature pertains to retrospective case series with varying treatment modalities using different types of botulinum toxin (e.g. Dysport ${ }^{\mathrm{TM}}$ or Botox ${ }^{\mathrm{TM}}$ or Prosign ${ }^{\mathrm{TM}}$ ) and different doses of the toxin.

\section{O B J E C T IVES}

The primary objective was to examine the efficacy of botulinum toxin therapy in the treatment of strabismus compared with alternative conservative or surgical treatment options. This review sought to ascertain those types of strabismus that particularly benefit from the use of botulinum toxin as a treatment option (such as small angle strabismus or strabismus with binocular potential, i.e. the potential to use both eyes together as a pair). The secondary objectives were to investigate the dose effect of botulinum toxin and the complication rates associated with botulinum toxin.

\section{METHODS}

\section{Criteria for considering studies for this review}

\section{Types of studies}

We included randomised controlled trials (RCTs) of treatment using botulinum toxin for strabismus. 


\section{Types of participants}

Participants with strabismus suitable for treatment with botulinum toxin to align the angle of deviation. This included adults and children with no age limit.

\section{Types of interventions}

We considered trials in which botulinum toxin of all makes, e.g. Dysport $^{\mathrm{TM}}$, Botox ${ }^{\mathrm{TM}}$, Prosign ${ }^{\mathrm{TM}}$ were compared to the following:

- strabismus surgery;

- botulinum toxin alternatives;

- conservative therapy; orthoptic exercises, prisms, lens therapy.

We made the following comparisons:

- single muscle versus multiple muscle injections of botulinum toxin;

- botulinum toxin in combination with conservative treatment versus conservative treatment alone;

- botulinum toxin versus other variant of botulinum toxin;

- botulinum toxin as an alternative to conservative treatment;

- botulinum toxin in combination with surgical treatment versus surgical treatment alone;

- botulinum toxin as an alternative to surgical treatment;

- botulinum toxin versus observation (no treatment);

- strabismus types with binocular potential versus those without binocular potential;

- small angle strabismus (less than 20 prism dioptres (PD)) versus large angle strabismus;

- level of dose of botulinum toxin and reported complications at each dose.

\section{Types of outcome measures}

\section{Primary outcomes}

- improved ocular alignment as measured by a reduction in the angle of deviation measured by prisms or the synoptophore.

We required a minimum of six months post-treatment follow up for assessment of primary outcomes.

\section{We classed outcomes as:}

- success: full control of angle of deviation within 10 PD of ortho (no deviation) with normal measures/ranges of binocular single vision (simultaneous perception, motor fusional vergence and stereopsis);

- satisfactory A: reduction in angle of deviation to within 20 PD of ortho with evidence of binocular single vision (simultaneous perception, motor fusional vergence or stereoacuity);

- satisfactory B: reduction in angle of deviation to within 20 PD of ortho without evidence of binocular single vision;

- fail: little or no change in angle of deviation and/or no improvement in binocular single vision measures.

We analysed separately the change in angle of deviation (continuous data) and the change in binocular single vision (categorical data) followed by a composite measure of the two (ordinal data).

\section{Secondary outcomes}

Secondary outcome measures included:

- achievement of binocular single vision as assessed by cover test, motor fusional vergences and stereoacuity.

\section{Adverse outcomes}

We considered the following adverse effects:

- induced ptosis;

- induced vertical deviation;

- subconjunctival haemorrhage;

- intolerable diplopia.

We categorized adverse effects as severe if they required further treatment, or minor if no further treatment was required.

Also we recorded the complications noted within two weeks of treatment in the included trials.

\section{Economic data}

We included details of the cost of any treatments where data were available.

\section{Quality of life data}

We considered any measure of participant or parent satisfaction relating to improvement in appearance or improvement to lifestyle.

\section{Search methods for identification of studies}

\section{Electronic searches}

We searched CENTRAL (which contains the Cochrane Eyes and Vision Trials Register) (2016, Issue 6), Ovid MEDLINE, Ovid MEDLINE In-Process and Other Non-Indexed Citations, Ovid MEDLINE Daily, Ovid OLDMEDLINE (January 1946 to July 2016), Embase (January 1980 to July 2016), Latin American and Caribbean Literature on Health Sciences (LILACS) (January 1982 to July 2016), the ISRCTN registry (www.isrctn.com/editAdvancedSearch), ClinicalTrials.gov (www.clinicaltrials.gov), and the World Health Organization (WHO) International Clinical Trials Registry Platform (ICTRP) (www.who.int/ictrp/search/en). We did not use any date or language restrictions in the electronic searches for trials. We last searched the electronic databases on 11 July 2016.

See: Appendices for details of search strategies for CENTRAL (Appendix 1), MEDLINE (Appendix 2), Embase (Appendix 3), LILACS (Appendix 4), ISRCTN (Appendix 5), ClinicalTrials.gov (Appendix 6) and the WHO ICTRP (Appendix 7).

\section{Searching other resources}

We handsearched the British and Irish Orthoptic Journal, Australian Orthoptic Journal, proceedings of the European Strabismological Association (ESA), International Strabismological Association (ISA) and International Orthoptic Association (IOA) (www.liv.ac.uk/ orthoptics/research/search.htm) and American Academy of Paediatric Ophthalmology and Strabismus meetings (AAPOS). These resources were searched from 1980 to 11 July 2016. We contacted researchers who are active in the field for information about further published or unpublished studies. We used the Pediatric Ophthalmology and Strabismus mailbase in the UK and USA. We screened the reference lists of publications. 


\section{Data collection and analysis}

\section{Selection of studies}

Both review authors independently screened the titles and abstracts obtained by the searches to establish whether they met the criteria defined as include, exclude and unsure. Included papers encompassed RCTs. Excluded papers encompassed case reports. Unsure encompassed papers that comprised non-RCTs and case series and a decision to include followed discussion between the review authors. Arbitration from the Cochrane editorial base was not required. Following this process, we obtained the full copies of definitely or potentially relevant studies. Where information was unclear we contacted the study authors. We documented the details of excluded studies in the 'Characteristics of excluded studies' table. We constructed a PRISMA diagram to illustrate the study selection process.

\section{Data extraction and management}

The two review authors independently extracted information relating to outcomes using paper data collection forms developed by Cochrane Eyes and Vision. We resolved discrepancies by discussion and entered data into Review Manager 5 (RevMan 5) (RevMan 2014).

We extracted the following details from the included studies:

- methods: inclusion and exclusion criteria, follow-up period;

- participants: age, previous treatment, strabismus type;

- interventions: type of botulinum toxin used, dose measure, number of injections;

- outcomes: ocular alignment and binocular function after a minimum of six months;

- adverse events and quality of life measures.

We used the GRADE approach to interpret findings (Langendam 2013), and employed the GRADE profiler (GRADEpro) to import data from RevMan 5 to create 'Summary of findings' tables (GRADEpro 2014). These tables provide outcome-specific information concerning the overall certainty of evidence from studies included in the comparisons, primary and secondary outcomes.

\section{Assessment of risk of bias in included studies}

We assessed study quality according to the methods set out in Chapter 8 of the Cochrane Handbook for Systematic Reviews of Interventions (Higgins 2011). We used the Cochrane tool for assessing risk of bias. We assessed sequence generation, allocation concealment, masking (blinding) of participants, personnel and outcome assessors, incomplete outcome data, selective outcome reporting and other sources of bias. We made judgements for each domain and graded each as either at low risk of bias, high risk of bias or unclear.

We used the GRADE approach to interpret findings and GRADEpro to import data from RevMan 5.3 to create 'Summary of findings' tables. These tables provide outcome-specific information concerning the overall certainty of evidence from RCTs included in the comparison, the magnitude of effect of the interventions examined and the sum of available data on the outcomes we considered. For assessments of the overall certainty of evidence for each outcome, we downgraded the evidence from high-certainty by one level for each serious study limitation, e.g. risk of bias, imprecision.

\section{Measures of treatment effect}

We considered the relative risk for dichotomous data relating to binocular single vision and the standardized mean difference for continuous data relating to measured change in angle of deviation.

\section{Unit of analysis issues}

We expected that studies may have consisted of parallel group trials or cross-over trials. Where we found both in the search, we considered these separately as botulinum toxin is known to have a longer lasting effect than the average three months expected for extraocular muscle function to fully recover. When analysing secondary outcome measures, if possible we re-evaluated studies that reported results 'per person' to convert results to 'per injection' as a more realistic indicator of prevalence.

\section{Dealing with missing data}

We contacted primary investigators/authors to obtain missing data. We allowed a time period of three months for response. We recorded non-response as missing data.

\section{Assessment of heterogeneity}

We assessed studies initially for heterogeneity using the $\mathrm{Chi}^{2}$ test. However, considering the expected heterogeneity, we considered the $1^{2}$ statistic value to quantify inconsistency. We deemed metaanalysis inappropriate on the basis of assessment of heterogeneity. Therefore, we provided a descriptive summary of results.

\section{Assessment of reporting biases}

There were insufficient trials to examine publication bias using a funnel plot.

\section{Data synthesis}

The results were heterogenous, hence we presented a descriptive summary of results.

\section{Subgroup analysis and investigation of heterogeneity}

We evaluated studies for clinical heterogeneity (variability in the participants or outcomes) and methodological heterogeneity (variability in trial design and quality).

\section{Sensitivity analysis}

We did not perform a sensitivity analysis to assess the sensitivity of the summary effect to the exclusion of trials assessed as inadequate in terms of concealment of randomisation or those with missing data or of questionable eligibility.

\section{Methods for future updates}

If trials become available in the future, we will include them in this review using the methods for the primary review. 


\section{RESULTS}

\section{Description of studies}

\section{Results of the search}

The electronic searches identified a total of 274 titles and abstracts. We requested the full text for a total of eight studies.

An update search was done in December 2011. After deduplication the search identified a total of 53 references. The Cochrane Information Specialist (CIS) (formerly known as Trials Search Coordinator) scanned the search results and removed 37 references which were irrelevant to the scope of the review. We assessed the remaining 16 references. Twelve references reported retrospective or case cohort studies and we excluded them. We obtained fulltext copies of the remaining four references and extracted further details.

Updates searches ran in July 2016 yielded a further 122 references (Figure 1). After 27 we removed duplicates, the CIS screened the remaining 95 records and removed 19 references which were not relevant to the scope of the review. We screened the remaining 76 references and obtained the full-text reports of six references for further assessment. We included two new studies (Chen 2013; Minguini 2012), and excluded two studies (Etezad Razavi 2014: Gursoy 2012). We identified two ongoing studies (Jain 2015; PACTR201508001241218), and contacted the trial authors for further information. We received responses from both trial teams, who confirmed the ongoing recruitment to these studies. 
Figure 1. Study flow diagram.

4 included studies in previous
version of the review (from
search as of 5 December 2012).
NCT01460355 study previously
awaiting classification now
incorporated into Minguini 2012.

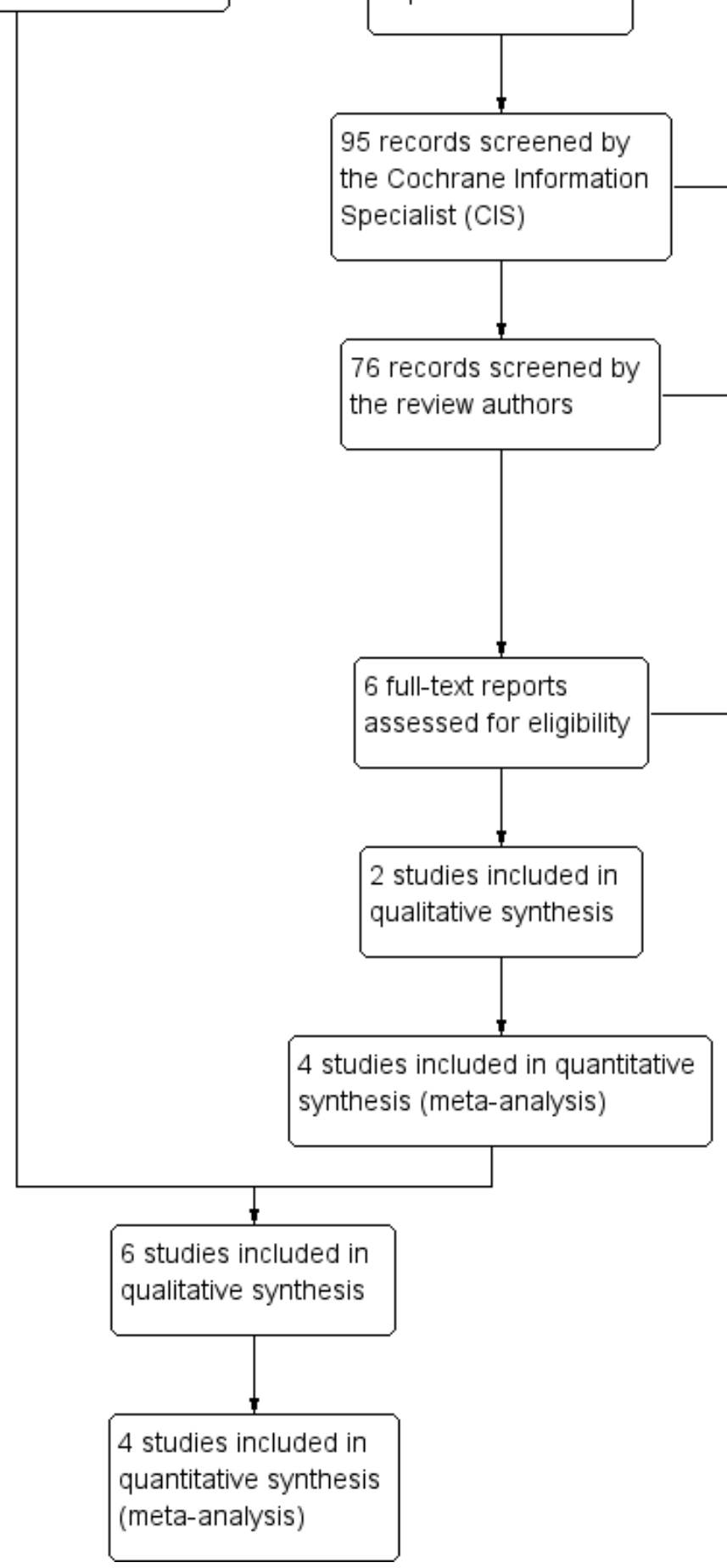

122 records identified through electronic database searching

19 records excluded by the CIS after initial screening

70 records excluded by the review authors as irrelevant

2 full-text articles excluded, with reasons.

2 ongoing studies to be assessed when data becomes available. 


\section{Included studies}

We included six trials and provided details below. Additional details can be found in the 'Characteristics of included studies' table.

Tejedor 1999 randomised 55 strabismic children with infantile esotropia receiving retreatment to two different treatment procedures: reoperation or botulinum toxin $\left(\right.$ Botox $\left.^{\mathrm{TM}}\right)$. This was a parallel RCT. The trial authors compared these groups to each other for percentage of successful motor outcome less than or equal to $(\leqq) 8$ prism dioptres (PD) and percentage change in deviation. The latter was calculated as preoperative deviation - postoperative deviation/preoperative deviation $\times 100 \%$. Inclusion and exclusion criteria were stipulated for the trial. Both groups were regarded as comparable as similarities were present for both groups regarding previous surgical procedures, mean age at initial surgery, average time lapse between first and second treatment, angle of deviation, refractive error and visual acuity measures. The trial achieved follow-up to a minimum of 36 months.

Tejedor 1998 randomised 47 strabismic children with acquired esotropia requiring retreatment to two different treatment procedures: reoperation or botulinum toxin (Botox ${ }^{\mathrm{TM}}$ ). This was a parallel RCT. These groups were compared to each other for percentage net change in distance deviation, the percentage of participants with successful motor outcome $\leqq 8 \mathrm{PD}$ and detectable fusion and stereopsis. Percentage net change was calculated as preoperative deviation - postoperative deviation/preoperative deviation $\times 100 \%$. Inclusion and exclusion criteria were stipulated for the trial. Both groups were regarded as homogenous as similarities were present for both groups regarding previous surgical procedures, mean age at initial surgery, average time lapse between first and second treatment, angle of deviation, refractive error and follow-up. The trial achieved follow-up of 20 to 38 months.

Lee 1994 randomised 54 participants with acute unilateral sixth nerve palsy into two groups: those receiving botulinum toxin (Dysport $^{\mathrm{TM}}$ ) to the isilateral medial rectus muscle and those observed for recovery with no invasive treatment. This was a parallel RCT. These groups were compared to each other for clinical diagnosis of recovery. A full recovery was defined as completely normal ocular rotations with full field of binocular single vision. Stable recovery was defined as normal binocular single vision with a minor asymptomatic abduction defect or a small asymptomatic vertical deviation. Non recovery was defined as a persisting esotropia in primary position with diplopia not controllable by normal amplitudes of fusional vergence. Two control participants were excluded and four were lost to follow-up. One botulinum toxin participant was lost to follow-up. Follow-up ranged from four to 42 months. Both groups were considered homogenous as gender, age range, aetiology of sixth nerve palsy, duration of symptoms and laterality of palsy were similar across both groups. The mean deviation of control participants was 17.8 PD and for botulinum toxin participants was 28.6 PD. The difference in deviation across both groups was significant $(P=0.02)$. Three of the 22 participants having botulinum toxin injection had one repeat injection.

Carruthers 1990 randomised 30 adult participants with esotropia or exotropia without binocular function requiring treatment by two different procedures: botulinum toxin (Botox ${ }^{\mathrm{TM}}$ ) or adjustable suture surgery. This RCT had a cross-over design. These groups were compared to each other for alignment of deviation $\leqq 10$ PD. In addition, percent net change was documented which was defined as preoperative deviation - postoperative deviation/preoperative deviation $\times 100 \%$. Inclusion and exclusion criteria were stipulated for the trial. Both groups had similar angles of deviation and similar numbers of esotropia and exotropia angles. The trial authors stated that five participants required further treatment. However they did not provide any information as to whether this constituted a crossover of treatment options. A statement was made that should crossover occur, a minimum six month period of follow-up would occur between treatments to allow for treatment effect.

From the 2016 update, we included two trials. Minguini 2012 reported the results of the NCT01460355 trial previously found in the 2011 search. They randomised 23 adult participants with concomitant horizontal deviations (esotropia or exotropia) of less than 50 PD requiring surgery. This was a double-masked RCT. Group $A$ received strabismus surgery plus botulinum toxin and group $B$ received strabismus surgery with placebo (hyaline solution). The groups were compared for net percentage change in angle of deviation from pre-operative to 1 day through to six to 12 months postoperative in addition to numbers achieving alignment less than 8 PD. Inclusion and exclusion criteria were stipulated for the trial. Both groups were regarded as homogenous as similarities were present for age at surgery, angle of pre-operative deviation, surgery ratio, best corrected visual acuity of either eye and percentage of severe amblyopia. The trial achieved follow-up to six to 12 months.

Chen 2013 randomised 47 participants with infantile esotropia that required treatment with botulinum toxin as their first treatment option. This was a two-group randomised trial. Group A received botulinum toxin with sodium hyaluronate and group $B$ received botulinum toxin only. The groups were compared for change in angle of deviation from pre-injection to 2 weeks, 3 months and 6 months post-injection in addition to numbers achieving less than 10 PD. Inclusion and exclusion criteria were stipulated for the trial. Both groups were regarded as homogenous as similarities were present for age at treatment, gender and pre-injection deviation. The trial achieved follow-up for 6 months.

\section{Excluded studies}

We excluded four studies in 2009 (Cooper 1991; Mills 2004; Sanjari 2008; Shallo-Hoffman 2006), three studies in 2011 (Li 2008; two reports by de Alba Campomanes 2010), and two studies in the 2016 update (Etezad Razavi 2014; Gursoy 2012).

For reasons of exclusion, see the 'Characteristics of excluded studies' table.

\section{Risk of bias in included studies}

We determined the risk of bias using the 'Risk of bias' assessment tool. This considers sequence generation, allocation concealment, masking of participants, personnel and outcome assessors, incomplete outcome date, selective outcome reporting and other potential threats to validity (Figure 2; Figure 3). Our 'Risk of bias' assessment deemed the included trials to be low risk for concealment of randomisation and we did not find incomplete data reporting. 
Figure 2. Methodological quality graph: review authors' judgements about each methodological quality item presented as percentages across all included studies.

\begin{tabular}{|c|c|c|c|c|}
\hline \multicolumn{5}{|l|}{ Random sequence generation (selection bias) } \\
\hline \multicolumn{5}{|l|}{ Allocation concealment (selection bias) } \\
\hline \multicolumn{5}{|l|}{ Blinding (performance bias and detection bias): Investigators } \\
\hline \multicolumn{5}{|l|}{ Blinding (performance bias and detection bias): Participants } \\
\hline \multicolumn{5}{|l|}{ Blinding (performance bias and detection bias): Personnel } \\
\hline \multicolumn{5}{|l|}{ Incomplete outcome data (attrition bias) } \\
\hline \multicolumn{5}{|l|}{ Selective reporting (reporting bias) } \\
\hline \multicolumn{5}{|l|}{ Other bias } \\
\hline & $25 \%$ & $50 \%$ & $75 \%$ & $100 \%$ \\
\hline$\square$ Unclear risk of bias & $\mid$ & sk of $b$ & & \\
\hline
\end{tabular}


Figure 3. Methodological quality summary: review authors' judgements about each methodological quality item for each included study.

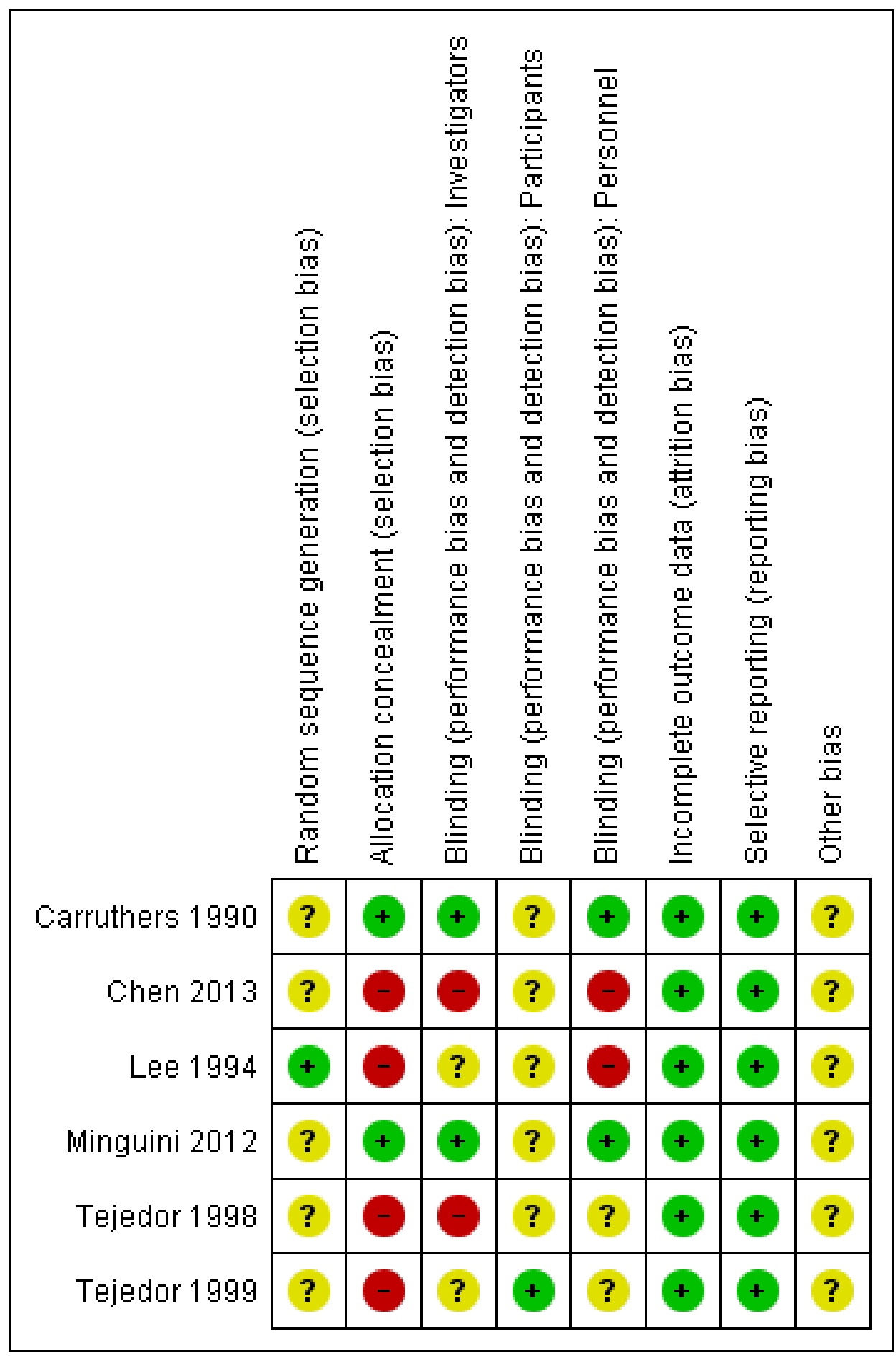

\section{Allocation}

Sequence generation was unclear in five trials (Carruthers 1990; Chen 2013; Minguini 2012; Tejedor 1998; Tejedor 1999). It was evident that randomisation had occurred but the included trials did not state the method by which they did this. The latter four trials were reported as having homogenous groups following randomisation in terms of similarities for pre-treatment angle of deviation, age, gender, etc. Lee 1994 specified the use of a random number table for sequence generation and thus we considered this domain as at low risk of bias.

Allocation sequence was adequately generated in Carruthers 1990, which constituted a low risk of bias as a research assistant allocated participants separately, and in Minguini 2012 who 
reported allocation as masked to surgeons. Allocation sequence was unclear or inadequately generated in the remaining trials.

\section{Blinding}

Carruthers 1990 achieved adequate prevention of knowledge of the allocated interventions in that the investigators and Orthoptist were masked to participant randomisation when undertaking the final evaluation of participants for outcome measures. Minguini 2012 achieved adequate masking as the trial authors reported masking of both surgeons providing the treatment and outcome assessors. The investigators were not masked to participant randomisation in the remaining trials. However it is unlikely that the absence of masking when evaluating final outcome of participants would be biased as the outcome measures related to actual measurements of eye position and responses to binocular assessments.

\section{Incomplete outcome data}

All studies adequately addressed incomplete outcome data, for which we determined a low risk of bias. The trial authors accounted for all participants throughout the trial and provided outcome data for participants that completed the trial and provided information on any participants that were lost to follow-up or excluded.

\section{Selective reporting}

We determined that all studies were free of suggestion of selective outcome reporting in that the trial authors addressed the outcomes specified in the methodology in the results of each study.

\section{Other potential sources of bias}

It was unclear whether any trial was completely free from potential sources of bias. Small numbers of participants were recruited in both adult trials of horizontal strabismus and additionally, the groups contained a mix of esotropic and exotropic participants which reduced numbers for direct comparison further (Carruthers 1990; Minguini 2012). It was unclear whether Lee 1994 was free from risk because of early discharge of some participants and lack of long-term follow-up across all participants for comparison. Three trials recruited low numbers of participants to the treatment groups, which could impact on direct comparisons of each trial group (Chen 2013; Tejedor 1998; Tejedor 1999).

\section{Effects of interventions}

See: Summary of findings for the main comparison Botulinum toxin versus surgery; Summary of findings 2 Botulinum toxin versus observation; Summary of findings 3 Surgery with botulinum toxin versus surgery without botulinum toxin; Summary of findings 4 Botulinum toxin with sodium hyaluronate versus botulinum toxin without sodium hyaluronate

\section{Botulinum toxin versus surgery}

\subsection{Primary outcome (improved ocular alignment \# 10 PD)}

Tejedor 1999 defined a satisfactory outcome at one year followup as $\leqq 8$ PD. This was achieved in $75 \%$ of the reoperation group and $67.85 \%$ of the botulinum toxin group for treatment of infantile esotropia. Percentage net change was $82.02 \%$ for the reoperation group and $78.71 \%$ for the botulinum group. Tejedor 1998 defined a satisfactory outcome at one year follow-up as $\leqq$ $8 \mathrm{PD}$. This was achieved in $75 \%$ of the reoperation group and
$69.56 \%$ of the botulinum toxin group for treatment of childhood strabismus. Percentage net change was $81.31 \%$ for the reoperation group and $73.45 \%$ for the botulinum group. Carruthers 1990 reported percentage net change in deviation at six months followup. This was achieved in $92.7 \%$ in the surgery group and $50.59 \%$ in the botulinum toxin group for treatment of adult strabismus. A satisfactory outcome was defined as within 10 PD which was achieved in $76.9 \%$ of the surgery group and $29.4 \%$ of the botulinum toxin group. This difference was noted as significant $(P=0.027)$. 'Summary of findings' table 1 shows a risk ratio (RR) effect size of $0.79,95 \%$ confidence interval (CI) 0.62 to $1.00 ; 132$ participants; 3 studies; 12 statistic $=55 \%$ (Summary of findings for the main comparison). We assessed the certainty of evidence as low. We downgraded certainty by one level for risk of bias and by one level for imprecision. Sequence generation was unclear; two trials were aware of participant randomisation and it was unclear for two trials how many had unilateral or bilateral injections of botulinum toxin.

\subsection{Secondary outcomes (achievement of binocular single vision/sensory fusion/stereopsis)}

Tejedor 1999 reported fusion (positive response with Worths four light test and Bagolini glasses test) and stereopsis (minimum of 480 seconds of arc) was present in $60.7 \%$ and $51.8 \%$ respectively of the reoperation group and $57.1 \%$ and $48.1 \%$ respectively of the botulinum toxin group. There were no statistically significant differences between these outcome measures across both groups. Tejedor 1998 reported fusion (positive response with Worths four light test) and stereopsis (minimum of 480 seconds of arc) was present in $62.5 \%$ and $54.16 \%$ respectively of the reoperation group and $56.52 \%$ and $47.82 \%$ respectively of the botulinum toxin group. There were no statistically significant differences between these outcome measures across both groups. Analysis for achievement of binocular single vision shows a RR effect size of $0.88,95 \% \mathrm{Cl} 0.63$ to $1.23 ; 102$ participants; 2 studies; 12 statistic $=0 \%$. We assessed the certainty of evidence as low. We downgraded certainty by one level for risk of bias and by one level for imprecision. Sequence generation was unclear, two trials were aware of participant randomisation and it was unclear for two trials how many had unilateral or bilateral injections of botulinum toxin. Carruthers 1990 included participants with no binocular single vision. Thus secondary outcomes for achievement of binocular single vision and fusion are not reported for this trial.

\section{Botulinum toxin versus observation}

\subsection{Primary outcome (improved ocular alignment \#10PD)}

Lee 1994 reported reduction in angle of deviation for acute onset sixth nerve palsy within 10 PD in $80 \%$ of control participants and $86 \%$ of botulinum toxin participants. The difference between both groups was not statistically significant. 'Summary of findings' table 2 shows a RR effect size of $1.19,95 \% \mathrm{Cl} 0.96$ to 1.48 ; 47 participants; 1 study (Summary of findings 2). We assessed the certainty of evidence as low. We downgraded certainty by one level for risk of bias. Investigators were aware of randomisation and it was not possible to mask investigators or participants to allocation.

\subsection{Secondary outcomes (achievement of binocular single vision/sensory fusion/stereopsis)}

Lee 1994 reported full recovery for sixth nerve palsy with achievement of binocular single vision in $80 \%$ of control participants and $95.5 \%$ of botulinum toxin participants (see Table 
1). The difference between both groups was not statistically significant. Analysis gave a RR effect size of $1.19,95 \% \mathrm{Cl} 0.96$ to 1.48 ; 47 participants; 1 study; $\left.\right|^{2}$ statistic $=0 \%$. We assessed the certainty of evidence as low. We downgraded certainty by one level for risk of bias. Investigators were aware of randomisation and it was not possible to mask investigators or participants to allocation.

\section{Surgery with botulinum toxin versus surgery without botulinum toxin}

\subsection{Primary outcome (improved ocular alignment \# 10PD)}

Minguini 2012 reported net percentage change in deviation at six to 12 months. A satisfactory change (angle within 20 PD) was achieved in $79.4 \%$ of the surgery plus botulinum toxin group compared to $68 \%$ in the surgery with hyaline solution group in the treatment of adult large angle strabismus. Target alignment was defined as within 8 PD. This was achieved in $33 \%$ of group A and $18 \%$ in group B. 'Summary of findings' table 3 shows a RR effect size of 1.83, 95\% $\mathrm{Cl} 0.41$ to $8.11 ; 23$ participants; 1 study; $\left.\right|^{2}$ statistic $=0 \%$ (Summary of findings 3 ). We assessed the certainty of evidence as low. We downgraded certainty by one level for imprecision. It was unclear how sequence generation was made.

\section{Botulinum toxin with sodium hyaluronate versus botulinum toxin without sodium hyaluronate}

\subsection{Primary outcome (improved ocular alignment \# 10PD)}

Chen 2013 reported change in angle of deviation from pre-injection to six months post-injection. Good alignment was defined as a deviation $<10$ PD. This was achieved in $30.4 \%$ of group A receiving botulinum toxin with sodium hyaluronate and $37.5 \%$ of group B receiving botulinum toxin only for treatment of infantile esotropia, with no significant difference between groups. 'Summary of findings' table 4 shows a RR effect size of $0.81,95 \% \mathrm{Cl} 0.36$ to $1.82 ; 47$ participants; 1 study; $1^{2}$ statistic $=0 \%$ (Summary of findings 4 ). We assessed the certainty of evidence as low. We downgraded certainty by one level for risk of bias in relation to allocation concealment, performance bias and detection bias. Sequence generation was not specified.

\section{Adverse events with use of botulinum toxin}

Tejedor 1999 reported transient ptosis in $37.03 \%$ of participants and transient vertical deviation in $18.51 \%$. Tejedor 1998 reported transient ptosis in $34.78 \%$ of participants and transient vertical deviation in $17.39 \%$. Carruthers 1990 did not report complications from use of botulinum toxin. Lee 1994 reported two cases with transient ptosis and four cases with transient vertical deviation with a total complication rate of $24 \%$ per injection and $27 \%$ per participant. Minguini 2012 reported ptosis in $41.6 \%$ and vertical deviation in $8.3 \%$ of group A with no complications described in group B. Chen 2013 reported complications of ptosis occurred in $2.2 \%$ of group $A$ and $20.8 \%$ of group $B$ which was significant $(P=0.008)$. Complications of vertical deviation occurred in $2.2 \%$ of group A and $2.1 \%$ of group B which was not significantly different. Analysis from five RCTs found transient ptosis occurring in 9 to $41.66 \%$ of participants and vertical deviation occurring in 8.3 to $18.51 \%$ of participants (Table 2). We assessed the certainty of evidence as low. We downgraded certainty by one level for imprecision because of mixed populations reducing numbers for comparison. Sequence generation was unclear for all but one trial (Lee 1994).

\section{DISCUSSION}

We included six randomised controlled trials in this review which compared botulinum toxin (Dysport ${ }^{\mathrm{TM}}$ or Botox ${ }^{\mathrm{TM}}$ or Prosign ${ }^{\mathrm{TM}}$ ) to either strabismus surgery or conservative treatment or adjuvant solution. The strabismus conditions treated in five trials were unlikely to alter with time without treatment (Carruthers 1990; Chen 2013; Minguini 2012; Tejedor 1998; Tejedor 1999), whereas the ocular motility condition in the remaining trial was likely to change spontaneously with time (Lee 1994). Risk calculations in anticipated absolute effects across the different types of interventions in these trials varied greatly. This is reflective of the heterogenous groups that comprised different intervention comparisons and different types of ocular motility conditions.

From these trials we were able to make the following comparisons based on the information available in the trial papers: botulinum toxin as an alternative to conservative treatment; botulinum toxin as an alternative to surgical treatment; surgery with or without adjuvant botulinum toxin, botulinum toxin with or without an adjuvant solution; strabismus types with binocular potential versus those without binocular potential; and reported complications. Notably, for this last comparison, we were unable to evaluate occurrence of complications across a range of different doses due to insufficient data in the trial results.

We found the certainty of evidence for all outcomes to be of moderate- or low-certainty primarily due to risk of bias and imprecise results because of lack of clarity in reporting trial methodology. We were able to address the primary outcome of improved ocular alignment as measured by a reduction in angle of deviation in all six trials. However, the main limiting factor for analysis was that results were not comparable across the trials due to different conditions being targeted by each trial plus the different types and doses of botulinum toxin used in each trial. We were able to address the primary classification outcome (success, satisfactory A, satisfactory B or fail) in one trial only (Lee 1994), as two trials provided the information for change in angle of deviation and binocular outcome separately (Tejedor 1998; Tejedor 1999), and there was no binocular outcome for the participants in the remaining three trials (Carruthers 1990; Chen 2013; Minguini 2012).

Secondary outcomes included achievement of binocular single vision and documentation of adverse effects. We determined the former outcome in three trials (Lee 1994; Tejedor 1998; Tejedor 1999), but again the results were not comparable due to differences in target condition and use of botulinum toxin. Four trials used Botox ${ }^{\text {TM }}$ (Carruthers 1990; Chen 2013; Tejedor 1998; Tejedor 1999), one trial used Dysport ${ }^{\mathrm{TM}}$ (Lee 1994), and one trial used Prosign ${ }^{\mathrm{TM}}$ (Minguini 2012), with varying doses utilised for each drug type. Hence the reported adverse effects were not comparable between trials. However, one trial compared the same type of botulinum toxin $\left(\right.$ Botox $^{\mathrm{TM}}$ ) with one group receiving Botox ${ }^{\mathrm{TM}}$ plus sodium hyaluronate and the second group receiving Botox ${ }^{\mathrm{TM}}$ only (Chen 2013). This trial showed a significant increase in ptosis as an adverse event in the Botox ${ }^{\mathrm{TM}}$ only group.

We were not able to obtain information on the cost of treatment or on measures of participant or parent satisfaction relating to treatment options and effectiveness of botulinum toxin. 


\section{Summary of main results}

There is a large body of literature on the subject of the use of botulinum toxin for the treatment of strabismus. Strabismus encompasses many types including esotropia, exotropia, vertical deviations, concomitant, acute onset and incomitant strabismus, plus strabismus with or without binocular vision. Therefore there are many variables that contribute to outcome after treatment. The literature on botulinum toxin consists predominantly of retrospective studies, cohort studies and case series, which are useful for describing the use of botulinum toxin in varying strabismus types but do not aid the establishment of reliable guidelines for the use of botulinum toxin as a treatment intervention or enable interpretation of treatment efficacy.

\section{Improved ocular alignment}

This was defined as measurement of a reduction in the angle of deviation by prisms or the synoptophore. All included trials achieved a reduction in angle of deviation using botulinum toxin to within 10 PD, ranging from 29.4\% (Carruthers 1990), 30.4\% (Chen 2013), 33.33\% (Minguini 2012), 66.66\% (Tejedor 1998), 69.56\% (Tejedor 1999), to $95.5 \%$ (Lee 1994). The lowest percentage was achieved in a strabismus condition that did not have binocular potential and this was significantly different from the reduction in angle of deviation achieved by surgery in this trial. The highest percentage was achieved in an ocular motility condition in which all participants had binocular potential. The reduction in angle of deviation achieved using botulinum toxin in three trials where participants had binocular potential showed no significant difference to the reduction in angle of deviation achieved by strabismus surgery (Tejedor 1998; Tejedor 1999), or by observation/ conservative treatment (Lee 1994).

Percentage net change in deviation was also calculated for five trials. For RCTs that compared botulinum toxin to reoperation, the percentage net change was not significant across both groups in which the strabismus type included presence of binocular vision as an outcome measure (Tejedor 1998; Tejedor 1999). For one trial where the strabismus type specifically excluded binocular vision, the percentage net change was significantly lower for the botulinum toxin group in comparison to the adjustable suture surgery group (Carruthers 1990). For a second trial in which the strabismus type had no demonstrable binocular vision, the net percentage change was greater for the surgery group combined with botulinum toxin compared to surgery alone (Minguini 2012). For the trial that compared botulinum toxin to observation for recent onset sixth nerve palsy, the change in ocular alignment was similar for both groups (Lee 1994).

Effect size of risk ratio (RR) varied from 0.79 (botulinum toxin versus surgery) to 0.81 (botulinum toxin with versus without sodium hyaluronate) to 1.19 (botulinum toxin versus observation) to 1.83 (surgery with or without botulinum toxin).

\section{Outcomes}

A successful outcome was classed as full control of the ocular deviation with a measurement within $10 \mathrm{PD}$ and with normal binocular single vision. This was achieved in $86 \%$ (botulinum toxin) and $80 \%$ (controls) respectively in participants from the trial of sixth nerve palsies (Lee 1994; Analysis 1.3). There was insufficient information provided in the trials by as outcomes for change in deviation and binocular vision were provided separately and not integrated (Tejedor 1998; Tejedor 1999; Analysis 2.1; Analysis 2.3). Carruthers 1990 and Minguini 2012 excluded participants with binocular vision potential and Chen 2013 did not report any information on binocular potential for their participants. Thus we could not apply our classification of successful outcome to these trials. Achievement of binocular vision was further classified in this review as satisfactory A (angle within 20 PD with binocular vision), satisfactory B (angle within 20 PD without binocular vision) and fail (little or no change in angle and without binocular vision). We were unable to use these classifications in Tejedor 1998 and Tejedor 1999 as measurements were not provided for the participants that failed to obtain a successful outcome plus outcomes for binocular vision were stated separately to outcomes for angle of deviation. Lee 1994 reported a successful outcome in $80 \%$ and $95.5 \%$, satisfactory A outcome in $12 \%$ and $0 \%$ and a failed outcome for $8 \%$ and $4.5 \%$ for non treatment and botulinum toxin treatment groups respectively (Analysis 2.2). The participants recruited in Carruthers 1990, Minguini 2012 and Chen 2013 had no reported binocular function and thus would not fall in the satisfactory A classification. We were unable to classify participants from the trial by Carruthers 1990 to satisfactory B or fail categories with reliability as deviations were stated as greater than 10 PD but with no ranges provided for these unsuccessful participants. $23.1 \%$ of the surgery group and $70.6 \%$ of the botulinum toxin group were either satisfactory B or fail classifications. Five of 30 participants were unsatisfied with their exotropia deviation and required further treatment. The range of final responses for all participants having botulinum toxin spread from 0 to $100 \%$ change in deviation (0 would be classed as a fail) and for participants having surgery, the spread was $67 \%$ to $100 \%$ change. Minguini 2012 reported 5/12 participants in group $A$ and $6 / 11$ participants in group $B$ as achieving satisfactory $B$ with angles of deviation of less than $20 \mathrm{PD}$, and $2 / 12$ participants in group $A$ plus $3 / 11$ participants in group $B$ achieving a fail with angles of deviation greater than 20 PD. Chen 2013 reported no data on angles of deviation greater than 10 PD at follow-up.

\section{Adverse outcomes}

Such outcomes may include induced transient ptosis, vertical deviation, subconjunctival haemorrhage and intolerable diplopia. The included trials reported transient ptosis in $23.4 \%, 37.03 \%$, $9 \%, 34.78 \%, 41.6 \%$ and $20.8 \%$ respectively and reported transient vertical deviation in $17.39 \%, 18.51 \%, 18 \%, 8.3 \%$ and $2.2 \%$ respectively for occurrence of adverse outcomes per participant (Chen 2013; Lee 1994; Minguini 2012; Tejedor 1998; Tejedor 1999). The overall complication rate ranged from $27 \%$ to $55.54 \%$ in these trials. Lee 1994 also reported the occurrence of adverse outcomes per injection as three participants underwent repeat botulinum toxin injection. The overall complication rate was $24 \%$ per injection. No other adverse outcomes were reported following the use of botulinum toxin in these trials. The duration of transient ptosis or vertical deviation was not stated in any of these trials. There were no adverse outcomes stated in any of the three trials relating to the strabismus surgery.

\section{Overall completeness and applicability of evidence}

Six RCTs of low-certainty evidence met the inclusion criteria of this review. Each trial related to a different type of strabismus or ocular motility condition; namely infantile esotropia, acute onset esotropia, sixth nerve palsy and horizontal strabismus without binocular vision. Hence this precluded a meta-analysis. It was not possible to ascertain information on dose effect as the six included 
trials used different types of botulinum toxin (Botox ${ }^{T M}$ versus Dysport $^{\mathrm{TM}}$ versus Prosign ${ }^{\mathrm{TM}}$ ) and different dosages. In addition, we were unable to obtain information on the cost of treatment or on measures of participant or parent satisfaction relating to treatment options and effectiveness. However, we described the outcome of treatment in each trial and ascertained the occurrence of adverse events in relation to the use of botulinum toxin.

\section{Quality of the evidence}

Downgrading of certainty of evidence was primarily related to risk of bias and/or imprecision. There was a lack of clarity on sequence generation or an inability to mask investigators and participants to allocation.

\section{Potential biases in the review process}

As far as we are aware we have minimised potential biases in the review process. We have followed the methods set out in the published protocol. The only amendment was to add in a summary of findings table and GRADE assessment as required by new Cochrane standards. To our knowledge, all potentially eligible studies were included - we implemeted an extensive search strategy with independent checks by both authors of the search results. See Figure 2 and Figure 3.

We obtained mixed results when we evaluated the included trials for risk of bias. One study was at low risk of bias in relation to sequence generation (Lee 1994). This was unclear for the other included trials. Two trials had a low risk of bias in relation to allocation concealment (Carruthers 1990; Minguini 2012). This was not achieved by the other trials. We considered all trials as at low risk of bias for the domains of masking, incomplete outcome bias and selective outcome reporting. However, we judged all trials as unclear in relation to the potential risk of other sources of bias. This was due to small participant numbers in each trial group for five trials (Carruthers 1990; Chen 2013; Minguini 2012; Tejedor 1998; Tejedor 1999), and due to early discharge of participants who had shown recovery before a six-month follow up period with lack of long-term follow up comparison across both groups (Lee 1994).

\section{Agreements and disagreements with other studies or reviews}

Our results are in general agreement with published observation studies of the use of botulinum toxin for the treatment of strabismus. Notably, these observation studies consider a variety of strabismus or ocular motility conditions (Crouch 2006; Dawson 2004b; Dawson 2005; Marsh 2003; Rayner 1999; Scott 1980) and each trial in this review also addressed a different strabismus or ocular motility condition. In addition, the included trials used different types and doses of botulinum toxin - similar to other observation studies published in the literature (Crouch 2006; Rayner 1999). It was thus not possible to compare these studies for agreement or disagreement of results. Botulinum toxin shows no difference in response in comparison to surgery in participants who required retreatment for acquired esotropia or infantile esotropia and in whom there was potential for binocular vision. Botulinum enhanced the effect of strabismus surgery in participants with strabismus without binocular potential. Botulinum toxin had a poorer effect in comparison to surgery in participants with strabismus without binocular potential. It showed no difference compared to no treatment in acute sixth nerve palsy and thus was deemed to have no prophylactic effect in this condition. The occurrence of adverse effects was similar to those reported in previous observation studies, particularly ptosis and induced vertical deviations (Crouch 2006; Marsh 2003; Rayner 1999).

\section{AUTHORS' CONCLUSIONS}

\section{Implications for practice}

Due to the limited number of RCTs identified in this review, the low-certainty of evidence and the variations in the conditions being treated, it has not been possible to address fully the outcomes of this review.

Without considering the type of strabismus or ocular motility being treated, botulinum toxin has been shown to reduce the angle of deviation by amounts comparable to surgical intervention. However, the type of strabismus is important when considering the secondary outcome of binocular vision. In horizontal strabismus types without potential for binocular vision there was a poorer treatment effect reported with botulinum toxin treatment compared to strabismus surgery. However, for horizontal strabismus types without potential for binocular vision, there was an improved treatment effect reported with combined strabismus surgery and botulinum toxin in comparison to surgery alone. In those strabismus types where there is potential for binocular vision, such as acute onset esotropia, sixth nerve palsy and infantile esotropia, botulinum toxin has been shown to achieve little difference in levels of binocular vision compared to surgery. Therefore on the basis of these studies botulinum toxin can be considered as an independent treatment option.

In terms of adverse events there was difficulty in evaluating the studies because of the varying doses and types of botulinum toxin used. For trials using comparable types and/or doses of Boto $^{\mathrm{TM}}$ the prevalence of reported adverse events were similar with approximately one third of cases developing transient ptosis and one fifth developing transient vertical deviation.

\section{Implications for research}

There is clearly a need for good quality trials to be conducted utilising botulinum toxin across the varying types of strabismus in order to improve the evidence base for the use of botulinum toxin as an independent management option. Standardisation is of utmost importance taking into consideration the types of botulinum toxin available and the dosages used as these aspects are not comparable. The presence or absence of binocular vision is also an important variable to consider in future trials.

\section{ACK N O WLEDGEMENTS}

Cochrane Eyes and Vision created and executed the search strategies. We thank John Lee, Catey Bunce, Stephen Gichuhi and Ian Marsh for their comments on the protocol or review or both. We thank Anupa Shah, Iris Gordon and Sue Elliott for their input in the development of this review. 


\section{REFERE N CES}

\section{References to studies included in this review}

\section{Carruthers 1990 \{published data only\}}

Carruthers JD, Kennedy RA, Bagaric D. Botulinum versus adjustable suture surgery in the treatment of horizontal misalignment in adult patients lacking fusion. Archives of Ophthalmology 1990;108(10):1432-5.

\section{Chen 2013 \{published data only\}}

Chen J, Deng D, Zhong H, Lin X, Kang Y, Wu H, et al. Botulinum toxin injections combined with or without sodium hyaluronate in the absence of electromyography for the treatment of infantile esotropia: a pilot study. Eye 2013;27(3):382-6.

\section{Lee 1994 \{published data only\}}

Lee J, Harris S, Cohen J, Cooper K, MacEwen C, Jones S. Results of a prospective randomized trial of botulinum toxin therapy in acute unilateral sixth nerve palsy. Journal of Pediatric Ophthalmology \& Strabismus 1994;31(5):283-6.

\section{Minguini 2012 \{published data only\}}

Minguini N, de Carvalho KM, Bosso FLS, Hirato FE, Kara-José N. Surgery with intraoperative botulinum toxin-A injection for the treatment of large-angle horizontal strabismus: a pilot study. Clinics 2012;67(3):279-82.

\section{Tejedor 1998 \{published data only\}}

Tejedor J, Rodríguez JM. Retreatment of children after surgery for acquired esotropia: reoperation versus botulinum toxin. British Journal of Ophthalmology 1998;82(2):110-4.

Tejedor 1999 \{published data only\}

Tejedor J, Rodríguez JM. Early retreatment of infantile esotropia: comparison of reoperation and botulinum toxin. British Journal of Ophthalmology 1999;83(7):783-7.

\section{References to studies excluded from this review}

\section{Cooper 1991 \{published data only\}}

Cooper K, Lee JP, MacEwen C, Jones S. Botulinum toxin A injection for acute sixth nerve palsy. Transactions of the 8th International Orthoptic Congress. 1991; Vol. VIII:336-40.

\section{de Alba Campomanes 2010 \{published data only\}}

* de Alba Campomanes AG, Binenbaum G, Campomanes Eguiarte $\mathrm{G}$. Comparison of botulinum toxin with surgery as primary treatment for infantile esotropia. Journal of AAPOS 2010;14(2):111-6.

de Alba Campomanes AG, Binenbaum G, Eguiarte GC. Comparison of botulinum toxin to surgery as primary treatment for infantile esotropia. Journal of AAPOS 2009;13(1):e4.

\section{Etezad Razavi 2014 \{published data only\}}

Etezad Razavi M, Sharifi M, Armanfar F. Efficacy of botulinum toxin in the treatment of intermittent exotropia. Strabismus 2014;22(4):176-81.

\section{Gursoy 2012 \{published data only\}}

Gursoy H, Basmak H, Sahin A, Yildirim N, Aydin Y, Colak E. Longterm follow-up of bilateral botulinum toxin injections versus bilateral recessions of the medial rectus muscles for treatment of infantile esotropia. Journal of AAPOS 2012;16(3):269-73.

\section{Li 2008 \{published data only\}}

Li Y, Wu X. [Observation of botulinum toxin A management in childhood with intermittent exotropia]. Zhonghua Yan Ke Za Zhi [Chinese Journal of Ophthalmology] 2008;44(11):967-71.

Mills 2004 \{published data only\}

Mills MD, Coats DK, Donahue SP, Wheeler DT, American Academy of Ophthamology. Strabismus surgery for adults. Ophthalmology 2004;111(6):1255-62.

\section{Sanjari 2008 \{published data only\}}

Sanjari MS, Falavarjani KG, Kashkouli MB, Aghai GH, Nojomi M, Rostami H. Botulinum toxin injection with and without electromyographic assistance for treatment of abducens nerve palsy: a pilot study. Journal of AAPOS 2008;12(3):259-62.

\section{Shallo-Hoffman 2006 \{published data only\}}

Shallo-Hoffman J, Acheson J, Bentley C, Bronstein AM. The influence of adaptation of visual motion detection in chronic sixth nerve palsy after treatment with botulinum toxin. Strabismus 2006;14(3):129-35.

\section{References to ongoing studies}

Jain 2015 \{published and unpublished data\}

Jain S, Anand S, Jones A. Intraoperative botulinum toxin in large angle strabismus. Journal of AAPOS 2015;19(4):e12.

PACTR201508001241218 \{published and unpublished data\} PACTR201508001241218. Botulinum neurotoxin as first line therapy in the management of childhood esotropia. www.pactr.org/ (accessed 23 April 2016).

\section{Additional references}

\section{Adams 2005}

Adams RJ, Hall HL, Courage ML. Long-term visual pathology in children with significant perinatal complications. Developmental Medicine and Child Neurology 2005;47(9):598-602.

\section{Bunting 2013}

Bunting HJ, Dawson EL, Lee JP, Adams GG. Role of inferior rectus botulinum toxin injection in vertical strabismus resulting from orbital pathology. Strabismus 2013;21(3):165-8.

\section{Campos 2000}

Campos EC, Schiavi C, Bellusci C. Critical age of botulinum toxin treatment in essential infantile esotropia. Journal of Pediatric Ophthalmology and Strabismus 2000;37(6):328-32. 


\section{Crouch 2006}

Crouch ER. Use of botulinum toxin in strabismus. Current Opinion in Ophthalmology 2006;17(5):435-40.

\section{Dawson 1999}

Dawson EL, Marshman WE, Adams GG. The role of botulinum toxin A in acute-onset esotropia. Ophthalmology 1999;106(9):1727-30.

\section{Dawson 2004a}

Dawson EL, Sainari A, Lee JP. Does botulinum toxin have a role in the treatment of secondary strabismus?. Transactions of the 29th European Strabismological Association; 2004 June 1-4; Izmir, Turkey. 2004:53-4.

\section{Dawson 2004b}

Dawson EL, Lee JP. Does botulinum toxin have a role in the treatment of small-angle esotropia?. Strabismus 2004;12(4):257-60

\section{Dawson 2005}

Dawson EL, Sainani A, Lee JP. Does botulinum toxin have a role in the treatment of secondary strabismus?. Strabismus 2005;13(2):71-3.

\section{Dawson 2012}

Dawson E, Ali N, Lee JP. Botulinum toxin injection into the superior rectus for treatment of strabismus. Strabismus 2012;20(1):24-5.

\section{Donnelly 2005}

Donnelly UM, Stewart NM, Hollinger M. Prevalence and outcomes of childhood visual disorders. Ophthalmic Epidemiology 2005;12(4):243-50.

\section{Gardner 2013}

Gardner R, Dawson EL, Adams GG, Lee JP. The use of botulinum toxin to treat strabismus following retinal detachment surgery. Strabismus 2013;21(1):8-12.

\section{Glanville 2006}

Glanville JM, Lefebvre C, Miles JN, Camosso-Stefinovic J. How to identify randomized controlled trials in MEDLINE: ten years on. Journal of the Medical Library Association 2006;94(2):130-6.

\section{GRADEpro 2014 [Computer program]}

GRADE Working Group, McMaster University. GRADEpro GDT. Version accessed 14 May 2016. Hamilton (ON): GRADE Working Group, McMaster University, 2014.

\section{Higgins 2011}

Higgins JP, Altman DG, Sterne JAC editor(s). Chapter 8: Assessing risk of bias in included studies. In: Higgins JP, Green S, editor(s). Cochrane Handbook for Systematic Reviews of Interventions Version 5.1.0 (updated March 2011). The Cochrane Collaboration, 2011. Available from handbook.cochrane.org.

Holmes 2001

Holmes JM, Leske DA, Christiansen SP. Initial treatment outcomes in chronic sixth nerve palsy. Journal of AAPOS 2001;5(6):370-6.

\section{Kerr 2001}

Kerr NC, Hoehn MB. Botulinum toxin for sixth nerve palsies in children with brain tumors. Journal of AAPOS 2001;5(1):21-5.

\section{Langendam 2013}

Langendam MW, AKL EA, Dahm P, Glasziou P, Guyatt G, Schünemann $\mathrm{HJ}$. Assessing and presenting summaries of evidence in Cochrane reviews. Systematic Reviews 2013;2:81.

\section{Marsh 2003}

Marsh IB. Botulinum toxin and the eye. Hospital Medicine 2003;64(8):464-7.

\section{McNeer 2003}

McNeer KW, Tucker MG, Guerry CH, Spencer RF. Incidence of stereopsis after treatment of infantile esotropia with botulinum toxin A. Journal of Pediatric Ophthalmology and Strabismus 2003;40(5):288-92.

\section{Ozkan 2006}

Ozkan SB, Topaloğlu A, Aydin S. The role of botulinum toxin $A$ in augmentation of the effect of recession and/or resection surgery. Journal of AAPOS 2006;10(2):124-7.

\section{Rayner 1999}

Rayner SA, Hollick EJ, Lee JP. Botulinum toxin in childhood strabismus. Strabismus 1999;7(2):103-11.

\section{RevMan 2014 [Computer program]}

Nordic Cochrane Centre, The Cochrane Collaboration. Review Manager 5 (RevMan 5). Version 5.3. Copenhagen: Nordic Cochrane Centre, The Cochrane Collaboration, 2014.

\section{Rowe 2004}

Rowe F, Noonan C, Nayak H. Use of botulinum toxin in preadolescent children. Transactions of the 10th International Orthoptic Congress; 2004 Nov 14-17; Melbourne. 2004; CD-ROM 187704024x.

\section{Rowe 2005}

Rowe FJ, Noonan CP, Nayak H. Botulinum toxin as a treatment option for decompensating intermittent strabismus in children. Transactions of the 30th European Strabismological Association; 2005 June 8-11; Killarney, Ireland. 2005:101-4.

\section{Sabetti 2003}

Sabetti L, D'Alessandri L, Salvatori K, Balestrazzi E. The use of botulinum toxin type $A$ in the treatment of chronic sixth ocular nerve palsy. Transactions of the 28th European Strabismological Association; 2003 June 19-21; Bergen. 2003:191-2

\section{Scott 1980}

Scott AB. Botulinum toxin injection into extraocular muscles as an alternative to strabismus surgery. Ophthalmology 1980;87(10):1044-9.

\section{Spencer 1997}

Spencer RF, Tucker MG, Choi RY, McNeer KW. Botulinum toxin management of childhood intermittent exotropia. Ophthalmology 1997;104(11):1762-7. 


\section{Strömland 1993}

Strömland K, Miller MT. Thalidomide embryopathy: revisited 27 years later. Acta Ophthalmologica 1993;71(2):238-45.

\section{Tejedor 2001}

Tejedor J, Rodríguez JM. Long-term outcome and predictor variables in the treatment of acquired esotropia with botulinum toxin. Investigative Ophthalmology and Visual Science 2001;42(11):2542-6.

\section{CHARACTERISTICS OF STUDIES}

Characteristics of included studies [ordered by study ID]

\section{References to other published versions of this review}

\section{Rowe 2009}

Rowe FJ, Noonan CP. Botulinum toxin for the treatment of strabismus. Cochrane Database of Systematic Reviews 2009, Issue 2. [DOI: 10.1002/14651858.CD006499.pub2]

\section{Rowe 2012}

Rowe FJ, Noonan CP. Botulinum toxin for the treatment of strabismus. Cochrane Database of Systematic Reviews 2012 Issue 2. [DOI: 10.1002/14651858.CD006499.pub3]

* Indicates the major publication for the study

\section{Carruthers 1990}

Methods Surgery versus botulinum toxin in adult strabismus without binocular function

Allocation: masked and randomised sequence

Masking: achieved for provider and outcome

Exclusions: 0

Losses: 0

Study design: RCT with cross-over of treatment if unsatisfactory result at 6 months.

\section{Participants}

Country: Canada

Randomised number: 30 participants (30 eyes)

Recruitment dates: Fall 1985 to 1988 i.e. 2.5 years.

Strabismus type: 20 exotropia (8 male and 12 female), 10 esotropia (4 male, 6 female)

Botulinim toxin (BT); 12 exotropia, 5 esotropia

Surgery; 8 exotropia, 5 esotropia

Angle of deviation; 60 prism dioptres (PD) of exotropia to 50 PD of esotropia

BT; 12 to 35 PD of esotropia (average 25.4 PD), 16 to 60 PD of exotropia (average 33.7 PD)

Surgery; 12 to 50 PD of esotropia (average 31.4 PD), 16 to 50 PD of exotropia (average 32.6 PD)

Age $>16$ years

BT; mean 33 years (17 to 58 years)

Surgery; mean 35 years (16 to 60 years)

Sex:

BT; 8 male, 9 female

Surgery; 4 male, 9 female

Inclusion criteria: angle greater than 10 PD, no binocular vision, > 16 years, attended follow-up appoint-

ments

Exclusion criteria: evidence of binocular vision

Repeat injections: undertaken in 9 participants

Interventions

Treatment:

Surgery; Unilateral 2 muscle or surgery with adjustable on recessed muscle

BT; 5 units Botox ${ }^{\mathrm{TM}}$. Participants offered repeat botulinum toxin (BT) injection if, at any time during 6 weeks following initial injection, the angle of deviation was not reduced below 10 PD. Re-injections provided twice for 5 participants, 3 times for 3 participants and four times for 1 participant.

Choice of eye for intervention: Side of intervention eye not specified 
Carruthers 1990 (Continued)

Duration: minimum 6 months follow-up. Participants were followed up at 1 day, 6 weeks, 3 months and 6 months postoperatively

Reduction in angle to < 10 PD:
Surgery; outcome achieved in $29.4 \%$ (5 participants)
BT; outcome achieved in $76.9 \%$ (10 participants)
\% net change (preoperative deviation - postoperative deviation / preoperative deviation x 100\%):
Surgery; $92.7 \%$ average change in deviation at 6 months
BT; $50.59 \%$ average change in deviation at 6 months
Choice of eye: Analysis of outcomes based on binocular measurement of change in angle of deviation
and reported adverse events monocularly in the intervention eye.
No complications reported
No costs reported
No quality of life indicators reported
Funding: support from the British Columbia Health Care Research Foundation.
Declarations of interest: the Smith-Kettlewell Instititue of Vision Sciences supplied the needle for the
trial. Alan Scott from the Smith-Kettlewell Institute supplied Oculinum.
Trial registration number: not specified.

Risk of bias

\begin{tabular}{|c|c|c|}
\hline Bias & Authors' judgement & Support for judgement \\
\hline $\begin{array}{l}\text { Random sequence genera- } \\
\text { tion (selection bias) }\end{array}$ & Unclear risk & Participants were randomised but how this was done was not stated \\
\hline $\begin{array}{l}\text { Allocation concealment } \\
\text { (selection bias) }\end{array}$ & Low risk & Participants were randomised by a research assistant \\
\hline $\begin{array}{l}\text { Blinding (performance } \\
\text { bias and detection bias) } \\
\text { Investigators }\end{array}$ & Low risk & $\begin{array}{l}\text { Investigators were masked (blinded) to participant allocation for final out- } \\
\text { come assessment }\end{array}$ \\
\hline $\begin{array}{l}\text { Blinding (performance } \\
\text { bias and detection bias) } \\
\text { Participants }\end{array}$ & Unclear risk & $\begin{array}{l}\text { It was not possible to mask participants to the different treatment options. } \\
\text { This was not judged to affect outcome measures }\end{array}$ \\
\hline $\begin{array}{l}\text { Blinding (performance } \\
\text { bias and detection bias) } \\
\text { Personnel }\end{array}$ & Low risk & $\begin{array}{l}\text { Investigators and the orthoptist were masked to participant randomisation } \\
\text { when undertaking the final evaluation of participants for outcome measures. }\end{array}$ \\
\hline $\begin{array}{l}\text { Incomplete outcome data } \\
\text { (attrition bias) } \\
\text { All outcomes }\end{array}$ & Low risk & $\begin{array}{l}\text { All participants were accounted for in the results with provision of outcome } \\
\text { data }\end{array}$ \\
\hline $\begin{array}{l}\text { Selective reporting (re- } \\
\text { porting bias) }\end{array}$ & Low risk & $\begin{array}{l}\text { The specified outcomes in the methodology were reported in the results, i.e. } \\
\text { percentage net change in deviation and success with final deviation }<10 \text { PD }\end{array}$ \\
\hline Other bias & Unclear risk & $\begin{array}{l}\text { Small numbers of participants across each trial group. Mix of esotropia and ex- } \\
\text { otropia participants further reduce numbers for comparison as these may re- } \\
\text { spond differently to use of BT or surgery }\end{array}$ \\
\hline
\end{tabular}




\begin{tabular}{|c|c|}
\hline \multirow[t]{6}{*}{ Methods } & Botulinum toxin with sodium hyaluronate versus botulinum toxin alone for infantile esotropia \\
\hline & Allocation: unknown \\
\hline & Masking: unsure for outcome \\
\hline & Exclusions: 0 \\
\hline & Losses: 0 \\
\hline & Study design: parallel RCT \\
\hline \multirow[t]{9}{*}{ Participants } & Country: China \\
\hline & Randomised number: 47 participants ( 94 eyes) $=23$ in group A, 24 in group B \\
\hline & Dates of recruitment: February 2008 to May 2011 \\
\hline & $\begin{array}{l}\text { Inclusion criteria: infantile esotropia with onset before } 6 \text { months of age. Botulinum toxin (BT) chosen as } \\
\text { first line treatment }\end{array}$ \\
\hline & $\begin{array}{l}\text { Exclusion criteria: orthotropic after refractive correction, Previous strabismus surgery, Systemic dis- } \\
\text { eases, Allergy to drugs. }\end{array}$ \\
\hline & Age: 12 to 81 months at time of injection. Group $A=38.0 \pm 17.5$. Group $B=35.8 \pm 20.7$ \\
\hline & Sex: 22 male, 25 female. Group A = 43.5\% male. Group B = 50\% male. \\
\hline & Angle of deviation: Group A = 35.0 \pm 15.7 PD, group B = 33.9 \pm 16.7 PD. \\
\hline & Follow-up to 6 months. \\
\hline
\end{tabular}

Interventions

\section{Group A:}

Bilateral injection of $0.05 \mathrm{~mL}$ Botox ${ }^{\mathrm{TM}}$ (2.5 to 3.75 units) with sodium hyaluronate (SH) in the absence of electromyography. Mix of BT solution with $\mathrm{SH}$ at volume ratio of 1:3.

Group B:

Bilateral injection of $0.03 \mathrm{~mL}$ Botox $^{\mathrm{TM}}$ ( 2.5 to 3.75 units) without sodium hyaluronate in the absence of electromyography.

Doses of 2.5 units for deviations < 30 PD. Doses of 3.75 units for deviations $>30$ PD.

Choice of eye for intervention: All received bilateral injections at 1 time point only.

Outcomes

Change in angle of deviation:

Group A $=30.4 \%$ achievement of angle $<10$ PD.

Group B $=37.5 \%$ achievement of angle $<10$ PD.

Presence of binocular vision not reported.

Choice of eye: analysis of outcomes based on binocular measurement of change in angle of deviation and reported adverse events monocularly for each intervention eye.

Vertical deviation: $2.2 \%$ in group A versus $2.1 \%$ in group $B$.

No report of duration of transient adverse events. 
Chen 2013 (Continued)

10 with monocular amblyopia, 5 with primary inferior oblique overaction, 3 with dissociated vertical deviation (DVD), 1 with inferior oblique overaction and DVD.

No costs reported.

No quality of life indicators reported.

Funding: support from Guangdong Provincial Scientific Technological Research Fund.

Declaration of interests: the authors declared no interests.

Trial registration number: not specified.

\section{Risk of bias}

\begin{tabular}{|c|c|c|}
\hline Bias & Authors' judgement & Support for judgement \\
\hline $\begin{array}{l}\text { Random sequence genera- } \\
\text { tion (selection bias) }\end{array}$ & Unclear risk & $\begin{array}{l}\text { Participants were randomised but how this was done was not stated. The two } \\
\text { groups were evaluated as being homogenous. }\end{array}$ \\
\hline $\begin{array}{l}\text { Allocation concealment } \\
\text { (selection bias) }\end{array}$ & High risk & Investigators were aware of participant randomisation. \\
\hline $\begin{array}{l}\text { Blinding (performance } \\
\text { bias and detection bias) } \\
\text { Investigators }\end{array}$ & High risk & Investigators did not appear to be masked to the different treatment options. \\
\hline $\begin{array}{l}\text { Blinding (performance } \\
\text { bias and detection bias) } \\
\text { Participants }\end{array}$ & Unclear risk & $\begin{array}{l}\text { Patinets could be masked to the treatment allocation but it was not stated of } \\
\text { they were informed of treatment group or not. }\end{array}$ \\
\hline $\begin{array}{l}\text { Blinding (performance } \\
\text { bias and detection bias) } \\
\text { Personnel }\end{array}$ & High risk & All preparations for treatment were made by the same treating physician. \\
\hline $\begin{array}{l}\text { Incomplete outcome data } \\
\text { (attrition bias) } \\
\text { All outcomes }\end{array}$ & Low risk & $\begin{array}{l}\text { All participants were accounted for in the results with provision of outcome } \\
\text { data. }\end{array}$ \\
\hline $\begin{array}{l}\text { Selective reporting (re- } \\
\text { porting bias) }\end{array}$ & Low risk & $\begin{array}{l}\text { The specified outcomes in the methodology were reported in the results, i.e. } \\
\text { change in angle of deviation and reporting of adverse events. }\end{array}$ \\
\hline Other bias & Unclear risk & Small number of participants across each trial group. \\
\hline
\end{tabular}

\section{Lee 1994}

Methods

Botulinum toxin versus observation for acute onset sixth cranial nerve palsy

Allocation: random number table

Masking: not achieved

Exclusions: 2 due to change in diagnosis

Losses: 5 lost to follow-up

Study design: parallel RCT

$\begin{array}{ll}\text { Participants } & \text { Country: UK } \\ & \text { Randomised number: } 54 \text { participants (54 eyes) - } 22 \text { in botulinum toxin (BT) group and } 25 \text { in control } \\ & \text { group }\end{array}$


Lee 1994 (Continued)

Dates of recruitment: August 1989 to August 1992

Age:

Controls; mean 61 years (24 to 86 years)

BT; mean 63 years ( 24 to 83 years)

Sex:

Controls; 12 males, 13 females

BT; 13 males, 9 females

Inclusion criteria: Hospital emergency department walk-in

Exclusion criteria: change in diagnosis

Duration of symptoms:

Controls; $\leqq 1$ week in $17, \leqq 2$ weeks in 6,3 weeks in 1 and 4 weeks in 1

$\mathrm{BT} ; \leqq 1$ week in $7, \leqq 2$ weeks in $9, \leqq 3$ weeks in 5 and 6 weeks in 1

Angle of deviation:

Controls; primary position at distance fixation fixing with nonparetic eye; mean 17.8 PD (4 to 40 PD)

BT; primary position at distance fixation fixing with nonparetic eye; mean 28.6 PD (6 to 70 PD)

Repeat injections; undertaken in 3 participants

Interventions

Treatment:

BT; 2.5 units Dysport ${ }^{\mathrm{TM}}$ to ipsilateral medial rectus muscle

3 participants had a second injection when first injection was inadequate

Control: observation

Duration: 4 to 42 months. Participants were followed up at 1 week, 6 weeks and 4 months as a mini-

mum

Discharged at 4 months if fully recovered

Choice of eye for intervention: Ipsilateral eye to the cranial nerve palsy - conventional choice

Outcomes

Full recovery: normal range of eye movement and full field binocular single vision

BT; $95.5 \%$ (20 participants)

Controls; $80 \%$ (16 participants)

Stable BSV: normal BSV with minor asymptomatic abduction deficit

BT; $4.5 \%$ (1 participant)

Controls; $16 \%$ (4 participants)

No recovery: persistent esotropia in primary gaze with diplopia

BT; $4.5 \%$ (1 participant) becoming 13.6\% (3 participants) due to recurrence of the sixth nerve palsy

over long term follow-up

Controls; $20 \%$ (5 participants)

Choice of eye: analysis of outcomes based on binocular measurement of change in angle of deviation and reported adverse events monocularly in the intervention eye.

Notes

Overall complication rate of $24 \%$ per injection (6/25) and $27 \%$ per participant (6/22)

2 cases of ptosis

4 cases of vertical deviation

No report of duration of transient adverse events

No costs reported

No quality of life indicators reported

Funding: none specified.

Declarations of interest: none specified.

Trial registration number: none specified. 
Lee 1994 (Continued)

Risk of bias

\begin{tabular}{|c|c|c|}
\hline Bias & Authors' judgement & Support for judgement \\
\hline $\begin{array}{l}\text { Random sequence genera- } \\
\text { tion (selection bias) }\end{array}$ & Low risk & Random number table was used \\
\hline $\begin{array}{l}\text { Allocation concealment } \\
\text { (selection bias) }\end{array}$ & High risk & Investigators were aware of participant randomisation \\
\hline $\begin{array}{l}\text { Blinding (performance } \\
\text { bias and detection bias) } \\
\text { Investigators }\end{array}$ & Unclear risk & Investigators did not appear to be masked to the different treatment options \\
\hline $\begin{array}{l}\text { Blinding (performance } \\
\text { bias and detection bias) } \\
\text { Participants }\end{array}$ & Unclear risk & $\begin{array}{l}\text { It was not possible to mask participants to the different treatment options. } \\
\text { This plus investigator knowledge of participant allocation to treatment group } \\
\text { was not judged to affect outcome measures }\end{array}$ \\
\hline $\begin{array}{l}\text { Blinding (performance } \\
\text { bias and detection bias) } \\
\text { Personnel }\end{array}$ & High risk & Investigators appeared aware of the different treatment options. \\
\hline $\begin{array}{l}\text { Incomplete outcome data } \\
\text { (attrition bias) } \\
\text { All outcomes }\end{array}$ & Low risk & $\begin{array}{l}\text { Participants lost to follow-up or excluded were accounted for along with par- } \\
\text { ticipants followed to designated follow-up periods. Despite loss of partici- } \\
\text { pants, a similar number of participants existed for each group in the trial }\end{array}$ \\
\hline $\begin{array}{l}\text { Selective reporting (re- } \\
\text { porting bias) }\end{array}$ & Low risk & $\begin{array}{l}\text { The specified outcomes in the methodology were reported in the results, i.e. } \\
\text { full recovery, stable BSV and non recovery of palsy }\end{array}$ \\
\hline Other bias & Unclear risk & Follow-up varied upwards from 4 months post onset of palsy \\
\hline
\end{tabular}

Minguini 2012

Methods Surgery with botulinum toxin versus surgery alone for large angle adult strabismus

Allocation: unknown

Masking: achieved for provider and outcome

Exclusions: 0

Losses: 2 from group A did not attend final follow-up visit

Study design: parallel RCT with double-masked assessment

Participants

Country: Brazil

Randomised number: 23 participants ( 23 eyes) $=12$ in group A, 114 in group B

Inclusion criteria: adults > 18 years of age with large angle (>50 PD) concomitant horizontal strabismus (esotropia or exotropia)

Exclusion criteria: previous strabismus surgery, neurological or systemic disease, oblique extraocular muscle over or under action, vertical deviation, dissociated vertical deviation (DVD), paretic or restrictive strabismus

Age: Group A = 34.3 \pm 6.4 . Group B $=28.8 \pm 9.8$

Sex: Group A = 6 females and 6 males. Group B $=6$ females and 5 males. 
Angle of deviation: Group A $=65.8 \pm 14.9$ PD with 6 exotropia and 6 esotropia, group B $=60.0 \pm 16.9$ PD with 7 exotropia and 4 esotropia.

Follow-up to 6 months.

\begin{tabular}{ll}
\hline Interventions & Group A: \\
Strabismus surgery plus injection of 5 units of botulinum toxin $\left(\operatorname{Prosign}^{\mathrm{TM}}\right)$ in $0.1 \mathrm{~mL}$ of hyaline solution. \\
Group B: \\
Strabismus surgery plus injection of $0.1 \mathrm{~mL}$ of hyaline solution. \\
Choice of eye for intervention: non-fixing eye - conventional choice
\end{tabular}

Outcomes
Percent net change in angle of deviation from pre-operative to 6 to 12 months postoperative:
Group B $=33.33 \%$ achievement of angle $<10$ PD.
Presence of binocular vision not reported.
Choice of eye: analysis of outcomes based on binocular measurement of change in angle of deviation
and reported adverse events monocularly in the intervention eye.

Notes
Pertical deviation: $8.3 \%$ in group A versus $0 \%$ in group B.
No report of duration of transient adverse events.
No costs reported.
No quality of life indicators reported.
Funding: none specified.
Declarations of interest: the authors declared no commercial or proprietary interests
Trial registration number: none specified

\section{Risk of bias}

\begin{tabular}{lll}
\hline Bias & Authors' judgement & Support for judgement \\
\hline $\begin{array}{l}\text { Random sequence genera- } \\
\text { tion (selection bias) }\end{array}$ & Unclear risk & Participants were randomised but how this was done was not stated. \\
\hline $\begin{array}{l}\text { Allocation concealment } \\
\text { (selection bias) }\end{array}$ & Low risk & Surgeons were masked to treatment allocation. \\
\hline $\begin{array}{l}\text { Blinding (performance } \\
\text { bias and detection bias) }\end{array}$ & Low risk & $\begin{array}{l}\text { Double-masked assessment with surgeons and assessors masked to alloca- } \\
\text { tion. }\end{array}$ \\
\hline $\begin{array}{l}\text { Blinding (performance } \\
\text { bias and detection bias) }\end{array}$ & Unclear risk & $\begin{array}{l}\text { Possible to mask participants to treatment allocation but not specified as to } \\
\text { whether this was done. }\end{array}$ \\
\hline $\begin{array}{l}\text { Blinding (performance } \\
\text { bias and detection bias) }\end{array}$ & Low risk & $\begin{array}{l}\text { Double-masked assessment with surgeons and assessors masked to alloca- } \\
\text { tion. }\end{array}$ \\
\hline
\end{tabular}


Minguini 2012 (Continued)

Personnel

\begin{tabular}{ll}
\hline $\begin{array}{l}\text { Incomplete outcome data } \\
\text { (attrition bias) }\end{array}$ & Low risk
\end{tabular}

(attrition bias)

date.

All outcomes

$\begin{array}{ll}\begin{array}{l}\text { Selective reporting (re- } \\ \text { porting bias) }\end{array} & \text { Low risk } \\ & \text { The specified outcomes in the methodology were reported in the results, i.e. } \\ \text { percentage net change in deviation and adverse events. }\end{array}$

Other bias Unclear risk Small numbers of participants across each trial group. Mix of esotropia and exotropia participants which may further reduce numbers for comparison as these may respond differently to use of surgery with/without botulinum toxin.

Tejedor 1998

Surgery versus botulinum toxin for childhood strabismus
Allocation: unknown
Masking: unsure for outcome
Exclusions: 0
Losses: 0
Study design: parallel RCT

Participants

Country: Spain

Randomised number: 47 participants - 24 in surgery group (38 eyes) and 23 in botulinum toxin (BT) group (number of eyes unclear)

Dates of recruitment: 1989 to 1994

Age at treatment in RCT: not specified

Age at initial surgery:

Surgery; mean 3.56 years (SD 1.53)

BT; mean 3.29 years (SD 1.28)

Time between initial and secondary treatment:

Surgery; mean 1.5 years (SD 0.98)

BT; mean 0.99 years $(0.84)$

Sex: not specified

Inclusion criteria: adequate; $<11$ years old, 1 previous operation, 10 PD angle

Exclusion criteria: adequate; Near/Distance disparity, Vertical deviation $>4$ PD, nystagmus, A/V pat-

tern, amblyopia > 4 lines

Pretreatment angle of deviation:

Surgery; mean 21.32 PD (SD 18.84) at near fixation and mean 18.58 PD (SD 18.52) at distance fixation BT; mean 22.16 PD (SD 16.83) at near fixation and mean 18.69 PD (SD 16.56) at distance fixation

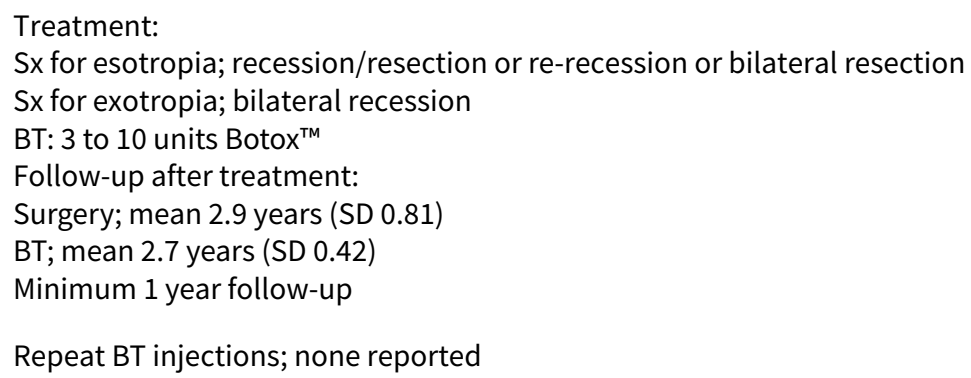


Tejedor 1998 (Continued)

Choice of eye for intervention:

Surgery; unilateral surgery if previous surgery was unilateral (10 participants), bilateral surgery if previous surgery was bilateral (14 participants)

BT; unilateral injection if dose required $<5$ units, bilateral injection if dose required $>5$ units

\begin{tabular}{|c|c|}
\hline \multirow[t]{5}{*}{ Outcomes } & $\begin{array}{l}\text { Reduction in angle to < } 8 \text { PD: } \\
\text { Surgery; outcome achieved in } 75 \% \text { (18 participants) } \\
\text { BT; outcome achieved in } 69.56 \% \text { (16 participants) }\end{array}$ \\
\hline & $\begin{array}{l}\text { Presence of binocular vision: } \\
\text { Surgery; outcome achieved in } 62.5 \% \text { ( } 15 \text { participants) } \\
\text { BT; outcome achieved in } 56.52 \% \text { ( } 13 \text { participants) }\end{array}$ \\
\hline & Reduction in angle of deviation and presence of binocular vision were considered separately \\
\hline & $\begin{array}{l}\text { Net } \% \text { change (preoperative deviation - postoperative deviation / preoperative deviation } \times 100 \% \text { ): } \\
\text { Surgery; mean } 81.31 \% \text { change in deviation at } 1 \text { year } \\
\text { BT; mean } 73.45 \% \text { change in deviation at } 1 \text { year }\end{array}$ \\
\hline & $\begin{array}{l}\text { Choice of eye: Analysis of outcomes based on binocular measurement of change in angle of deviation } \\
\text { and reported adverse events monocularly in each intervention eye. }\end{array}$ \\
\hline \multirow[t]{7}{*}{ Notes } & $\begin{array}{l}\text { Overall complication rate of } 52.17 \%(12 / 23) \text { per participant } \\
\text { Ptosis; } 34.78 \%(8 / 23) \\
\text { Vertical; } 17.39 \%(4 / 23)\end{array}$ \\
\hline & No report of duration of transient adverse events \\
\hline & No costs reported \\
\hline & No quality of life indicators reported \\
\hline & Funding: none specified \\
\hline & Declarations of interest: none specified \\
\hline & Trial registration number: none specified \\
\hline
\end{tabular}

\section{Risk of bias}

Bias Authors' judgement Support for judgement

Random sequence genera- Unclear risk Participants were randomised but how this was done was not stated. The two tion (selection bias) groups were evaluated as being homogenous

\begin{tabular}{lll}
\hline $\begin{array}{l}\text { Allocation concealment } \\
\text { (selection bias) }\end{array}$ & High risk & Investigators were aware of participant randomisation \\
\hline $\begin{array}{l}\text { Blinding (performance } \\
\text { bias and detection bias) } \\
\text { Investigators }\end{array}$ & High risk & Investigators did not appear to be masked to the different treatment options \\
\end{tabular}

\begin{tabular}{|c|c|c|}
\hline $\begin{array}{l}\text { Blinding (performance } \\
\text { bias and detection bias) } \\
\text { Participants }\end{array}$ & Unclear risk & $\begin{array}{l}\text { It was not possible to mask participants to the different treatment options. } \\
\text { This plus investigator knowledge of participant allocation to treatment group } \\
\text { was not judged to affect outcome measures }\end{array}$ \\
\hline
\end{tabular}

\begin{tabular}{lll}
\hline $\begin{array}{l}\text { Blinding (performance } \\
\text { bias and detection bias) } \\
\text { Personnel }\end{array}$ & Unclear risk & This was not stated \\
\hline $\begin{array}{l}\text { Incomplete outcome data } \\
\text { (attrition bias) }\end{array}$ & Low risk & $\begin{array}{l}\text { All participants were accounted for in the results with provision of outcome } \\
\text { data }\end{array}$ \\
\hline
\end{tabular}


Tejedor 1998 (Continued)

All outcomes

\section{Selective reporting (re- Low risk} porting bias)

The specified outcomes in the methodology were reported in the results, i.e. percentage mean change in deviation, successful motor outcome with final deviation < 8 PD and successful sensory outcome with positive fusion and stereo response

Other bias Unclear risk Small numbers of participants across each trial group

Tejedor 1999

$\begin{array}{ll}\text { Methods } & \text { Allocation: unclear } \\ & \text { Masking: unsure for outcome } \\ & \text { Exclusions: } 0 \\ & \text { Losses: } 0 \\ & \text { Study design: parallel RCT }\end{array}$

\begin{tabular}{|c|c|}
\hline Participants & $\begin{array}{l}\text { Country: Spain } \\
\text { Randomised number: } 55 \text { participants - } 28 \text { in surgery group ( } 56 \text { eyes) and } 27 \text { in BT group (number of } \\
\text { eves unclear) }\end{array}$ \\
\hline
\end{tabular}
eyes unclear)

Dates of recruitment: 1990 to 1994

Age at retreatment in RCT; not specified

Age at initial surgery:

Surgery; mean 15.33 months (SD 3.31)

BT; mean 14.25 months (SD 3.12)

Time between initial and secondary treatment:

Surgery; mean 6.25 months (SD 1.60)

BT; mean 5.50 months (1.23)

Sex:

Surgery; 13 females, 15 males

BT; 12 females, 15 males

Inclusion criteria: adequate; esotropia < 6 months, no accommodative element, retreated within 12 months

Exclusion criteria: adequate; accom element present, vertical > 4 PD, medical or neuro disease

Pretreatment angle of deviation:

Surgery; mean 28.87 PD (SD 12.41) at near fixation and mean 25.40 PD (SD 11.35) at distance fixation BT; mean 24.12 PD (SD 16.02) at near fixation and mean 20.27 PD (SD 15.15) at distance fixation

Treatment:

Surgery for esotropia; bilateral LR resection \pm bilateral MR recession

Surgery for exotropia; bilateral LR recession or MR advancement

BT: 3 to 12.5 units Botox ${ }^{\mathrm{TM}}$

Follow-up after retreatment:

Surgery; mean 3.75 years (SD 0.12)

$\mathrm{BT}$; mean 3.5 years (SD 0.21)

Minimum 6 month follow-up

Repeat BT injections: none reported

Choice of eye for intervention:

Surgery; all had bilateral surgery as previous surgery was bilateral (28 participants, 56 eyes) 
Tejedor 1999 (Continued)

BT; unilateral injection if dose required $<5$ units, bilateral injection if dose required $>5$ units

Reduction in angle to < 8 PD:
Surgery; outcome achieved in $75 \%$ (21 participants)
BT; outcome achieved in $66.66 \%$ (18 participants)
Presence of binocular vision:
Surgery; outcome achieved in $60.71 \%$ (17 participants)
BT; outcome achieved in $51.85 \%$ (14 participants)
Reduction in angle of deviation and presence of binocular vision were considered separately
Net \% change (preoperative deviation - postoperative deviation / preoperative deviation x $100 \%$ ):
Surgery; mean $82.02 \%$ change in deviation at 6 months
BT; mean $78.71 \%$ change in deviation at 6 months
Choice of eye: analysis of outcomes based on binocular measurement of change in angle of deviation
and reported adverse events monocularly in each intervention eye.

and reported adverse events monocularly in each intervention eye.

$\begin{array}{ll}\text { Notes } & \text { Overall complication rate of } 55.54 \%(15 / 27) \text { per participant } \\ \text { Ptosis; } 37.03 \%(10 / 27) \\ \text { Vertical; } 18.51 \%(5 / 27) \\ \text { No report of duration of transient adverse events } \\ \text { No costs reported } \\ \text { No quality of life indicators reported } \\ \text { Funding: none specified } \\ \text { Declarations of interest: the authors declare no conflicts of interest } \\ \text { Trial registration number: none specified }\end{array}$

\section{Risk of bias}

\begin{tabular}{|c|c|c|}
\hline Bias & Authors' judgement & Support for judgement \\
\hline $\begin{array}{l}\text { Random sequence genera- } \\
\text { tion (selection bias) }\end{array}$ & Unclear risk & $\begin{array}{l}\text { Participants were randomised but how this was done was not stated. The two } \\
\text { groups were evaluated as being homogenous }\end{array}$ \\
\hline $\begin{array}{l}\text { Allocation concealment } \\
\text { (selection bias) }\end{array}$ & High risk & Investigators were aware of participant randomisation \\
\hline $\begin{array}{l}\text { Blinding (performance } \\
\text { bias and detection bias) } \\
\text { Investigators }\end{array}$ & Unclear risk & Investigators did not appear to be masked to the different treatment options \\
\hline $\begin{array}{l}\text { Blinding (performance } \\
\text { bias and detection bias) } \\
\text { Participants }\end{array}$ & Low risk & $\begin{array}{l}\text { It was not possible to mask participants to the different treatment options. } \\
\text { This plus investigator knowledge of participant allocation to treatment group } \\
\text { was not judged to affect outcome measures }\end{array}$ \\
\hline $\begin{array}{l}\text { Blinding (performance } \\
\text { bias and detection bias) } \\
\text { Personnel }\end{array}$ & Unclear risk & This was not stated \\
\hline $\begin{array}{l}\text { Incomplete outcome data } \\
\text { (attrition bias) } \\
\text { All outcomes }\end{array}$ & Low risk & $\begin{array}{l}\text { All participants were accounted for in the results with provision of outcome } \\
\text { data }\end{array}$ \\
\hline $\begin{array}{l}\text { Selective reporting (re- } \\
\text { porting bias) }\end{array}$ & Low risk & $\begin{array}{l}\text { The specified outcomes in the methodology were reported in the results, i.e. } \\
\text { percentage mean change in deviation, successful motor outcome with final }\end{array}$ \\
\hline
\end{tabular}


Tejedor 1999 (Continued)

deviation < 8 PD and successful sensory outcome with positive fusion and stereo response

Other bias Unclear risk Small numbers of participants across each trial group

Abbreviations: A\&E: accident and emergency department; AV: A or V pattern; Accom: accommodation; BSV: binocular single vision; BT: botulinum toxin; BV: binocular vision; F: female; F/U: follow-up; LR: lateral rectus muscle; M: male; MR: medial rectus muscle; N/D: near/ distance; PD: prism dioptres; RCT: randomised controlled trial; Sx: surgery.

\section{Characteristics of excluded studies [ordered by study ID]}

\begin{tabular}{ll}
\hline Study & Reason for exclusion \\
\hline Cooper 1991 & $\begin{array}{l}\text { The paper consisted of the preliminary findings for the paper by Lee 1994 documented in the 'In- } \\
\text { cluded studies' }\end{array}$ \\
\hline de Alba Campomanes 2010 & Prospective, non-randomised comparative study and not a randomised controlled trial (RCT) \\
\hline Etezad Razavi 2014 & Prospective, non-randomised comparative study and not a RCT \\
\hline Gursoy 2012 & $\begin{array}{l}\text { Retrospective review of botulinum toxin versus strabismus surgery outcomes for treatment of es- } \\
\text { otropia }\end{array}$ \\
\hline Li 2008 & Prospective, non-randomised clinical study and not a RCT \\
\hline Mills 2004 & \begin{tabular}{l} 
Review article and not a RCT in itself \\
\hline Sanjari 2008
\end{tabular} \\
\hline Case series and not a RCT \\
\hline $\begin{array}{l}\text { Study of the influence of adaptation in people with chronic sixth nerve palsy having botulinum tox- } \\
\text { in. Results not applicable to the objectives of this review }\end{array}$
\end{tabular}

Abbreviations: RCT: randomised controlled trial.

Characteristics of ongoing studies [ordered by study ID]

\begin{tabular}{ll}
\hline Jain $\mathbf{2 0 1 5}$ & \\
\hline Trial name or title & Intraoperative botulinum toxin in large angle strabismus \\
\hline Methods & Large angle strabismus \\
\hline Interventions & Surgery alone versus surgery with botulinum toxin \\
\hline Outcomes & Postoperative reduction in angle of deviation plus adverse events from botulinum toxin \\
\hline Starting date & August 2012 \\
\hline Contact information & Chief investigator: Mr S Jain, Royal Free Hospital, London \\
\hline Notes & - \\
\hline
\end{tabular}


PACTR201508001241218

\begin{tabular}{ll}
\hline Trial name or title & Botulinum toxin in childhood strabismus \\
\hline Methods & Prospective randomised parallel arm controlled trial \\
\hline Participants & Children aged 6 months to 6 years with esotropia \\
\hline Interventions & Botulinum toxin versus bilateral medial rectus muscle recession surgery \\
\hline Outcomes & Degree of alignment; cost effectiveness comparison; adverse events \\
\hline Starting date & February 2015 \\
\hline Contact information & Chief investigator: Mr I Mayet, St John Eye Hospital, Soweto, Johannesburg \\
\hline Notes & -
\end{tabular}

\section{DATA AND ANALYSES}

\section{Comparison 1. Botulinum toxin versus surgery}

\begin{tabular}{|c|c|c|c|c|}
\hline Outcome or subgroup title & No. of studies & $\begin{array}{l}\text { No. of partici- } \\
\text { pants }\end{array}$ & Statistical method & Effect size \\
\hline $\begin{array}{l}1 \text { Primary outcome - improved ocular } \\
\text { alignment } \leq 10 \text { PD }\end{array}$ & 3 & & $\begin{array}{l}\text { Risk Ratio (M-H, Fixed, 95\% } \\
\mathrm{Cl})\end{array}$ & Subtotals only \\
\hline 1.1 Children & 2 & 102 & $\begin{array}{l}\text { Risk Ratio (M-H, Fixed, 95\% } \\
\mathrm{Cl})\end{array}$ & $0.91[0.71,1.16]$ \\
\hline 1.2 Adults & 1 & 30 & $\begin{array}{l}\text { Risk Ratio (M-H, Fixed, 95\% } \\
\mathrm{Cl})\end{array}$ & $0.38[0.17,0.85]$ \\
\hline $\begin{array}{l}2 \text { Secondary outcome - achievement } \\
\text { of binocular single vision }\end{array}$ & 2 & 102 & $\begin{array}{l}\text { Risk Ratio (M-H, Fixed, 95\% } \\
\mathrm{Cl})\end{array}$ & $0.88[0.63,1.23]$ \\
\hline $\begin{array}{l}3 \text { Secondary outcome - achievement } \\
\text { of 'sensory' fusion }\end{array}$ & 2 & 102 & $\begin{array}{l}\text { Risk Ratio (M-H, Fixed, 95\% } \\
\mathrm{Cl})\end{array}$ & $0.88[0.63,1.23]$ \\
\hline $\begin{array}{l}4 \text { Secondary outcome - achievement } \\
\text { of stereopsis }\end{array}$ & 2 & 102 & $\begin{array}{l}\text { Risk Ratio (M-H, Fixed, 95\% } \\
\mathrm{Cl} \text { ) }\end{array}$ & $0.86[0.59,1.25]$ \\
\hline
\end{tabular}


Analysis 1.1. Comparison 1 Botulinum toxin versus surgery,

Outcome 1 Primary outcome - improved ocular alignment $\leq 10$ PD.

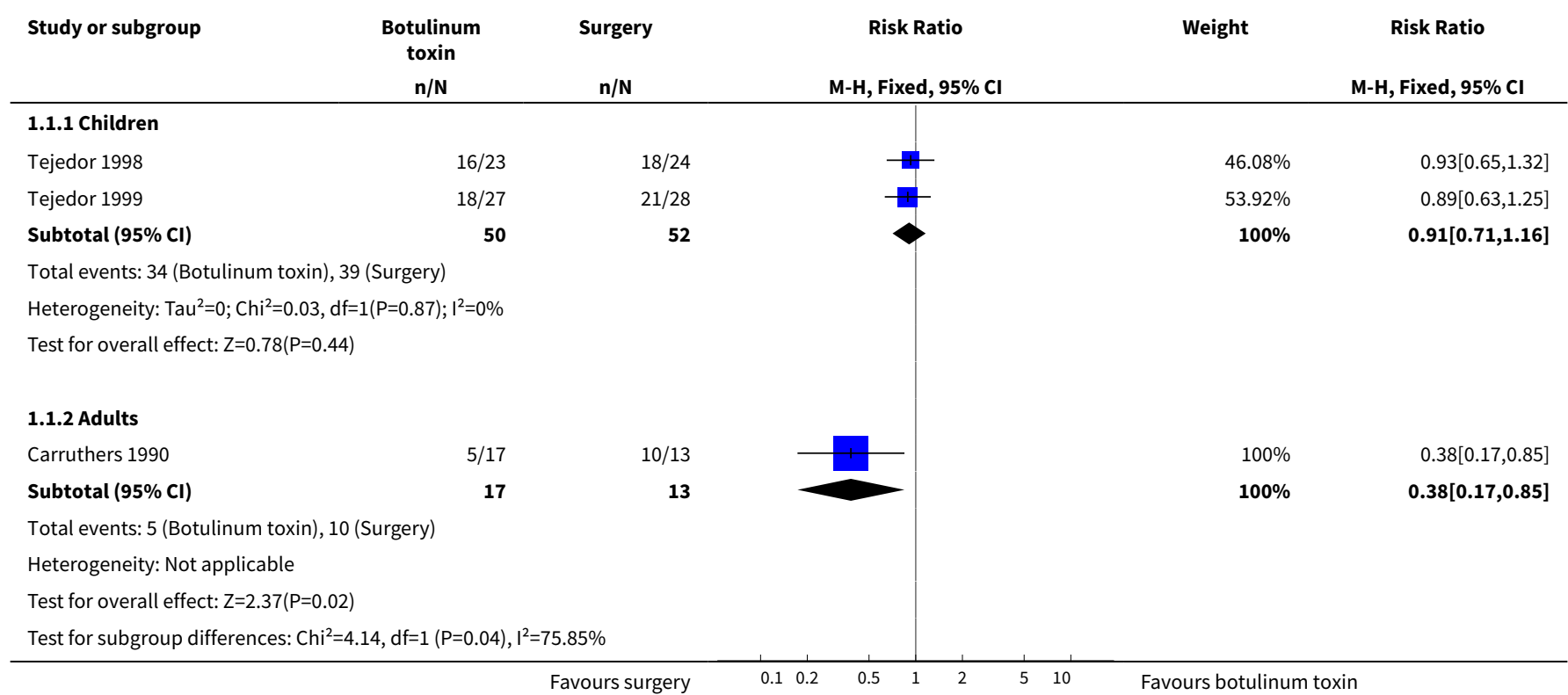

Analysis 1.2. Comparison 1 Botulinum toxin versus surgery, Outcome 2 Secondary outcome - achievement of binocular single vision.

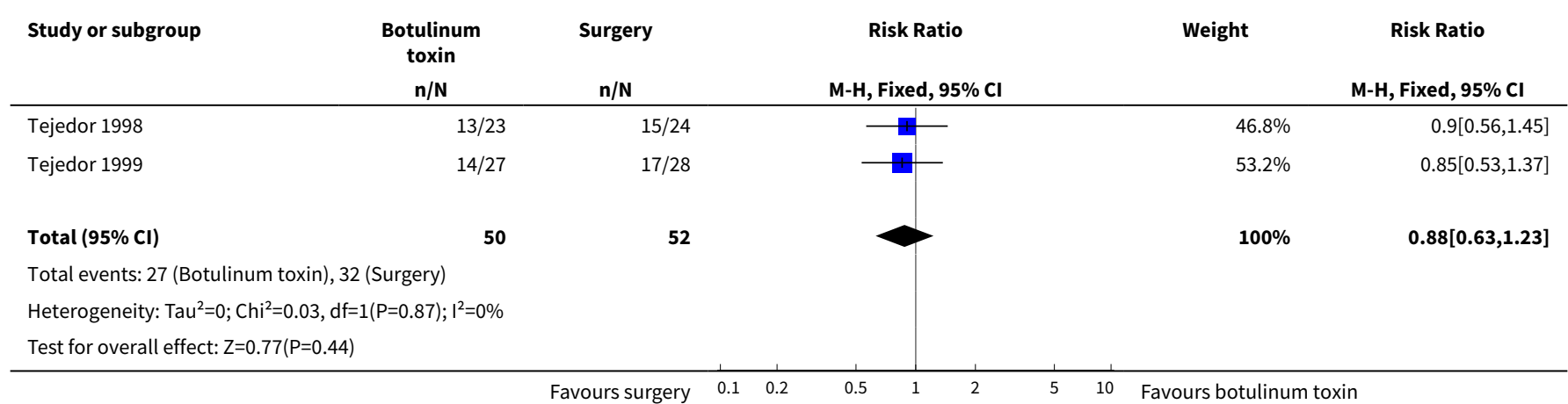

Analysis 1.3. Comparison 1 Botulinum toxin versus surgery, Outcome 3 Secondary outcome - achievement of 'sensory' fusion.

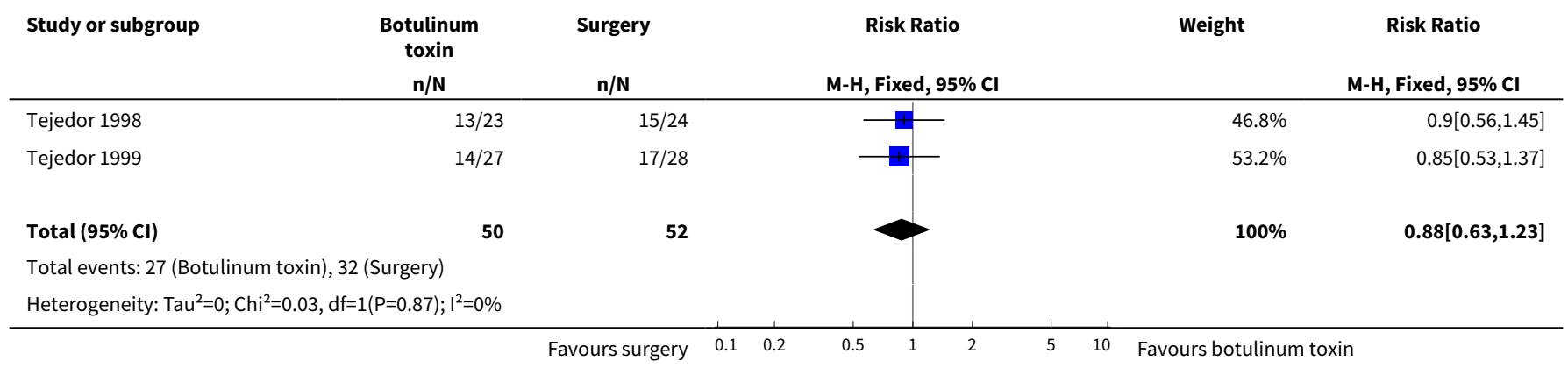




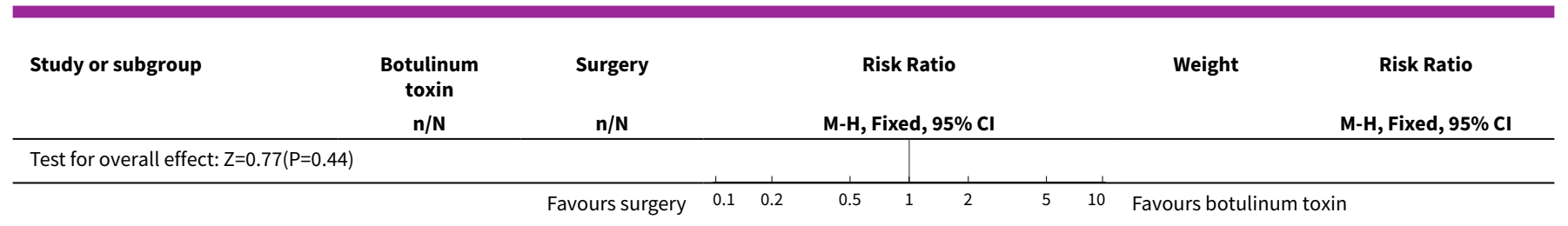

Analysis 1.4. Comparison 1 Botulinum toxin versus surgery, Outcome 4 Secondary outcome - achievement of stereopsis.

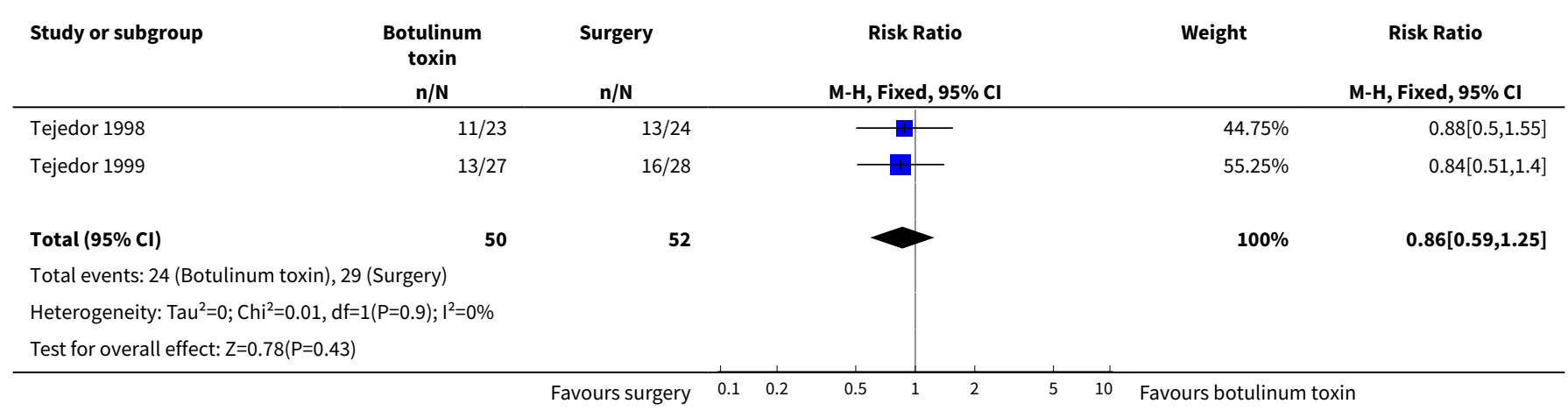

\section{Comparison 2. Botulinum toxin versus observation}

\begin{tabular}{|c|c|c|c|c|}
\hline Outcome or subgroup title & No. of studies & $\begin{array}{l}\text { No. of partici- } \\
\text { pants }\end{array}$ & Statistical method & Effect size \\
\hline $\begin{array}{l}1 \text { Primary outcome - improvement of ocular } \\
\text { alignment } \leq 10 \text { PD }\end{array}$ & 1 & & $\begin{array}{l}\text { Risk Ratio (M-H, Fixed, } \\
95 \% \mathrm{Cl})\end{array}$ & $\begin{array}{l}\text { Totals not select- } \\
\text { ed }\end{array}$ \\
\hline 2 Secondary outcome - classification & & & Other data & No numeric data \\
\hline $\begin{array}{l}3 \text { Secondary outcome - achievement of } \\
\text { binocular single vision }\end{array}$ & 1 & & $\begin{array}{l}\text { Risk Ratio (M-H, Fixed, } \\
95 \% \mathrm{Cl})\end{array}$ & $\begin{array}{l}\text { Totals not select- } \\
\text { ed }\end{array}$ \\
\hline
\end{tabular}

Analysis 2.1. Comparison 2 Botulinum toxin versus observation, Outcome 1 Primary outcome - improvement of ocular alignment $\leq 10$ PD.

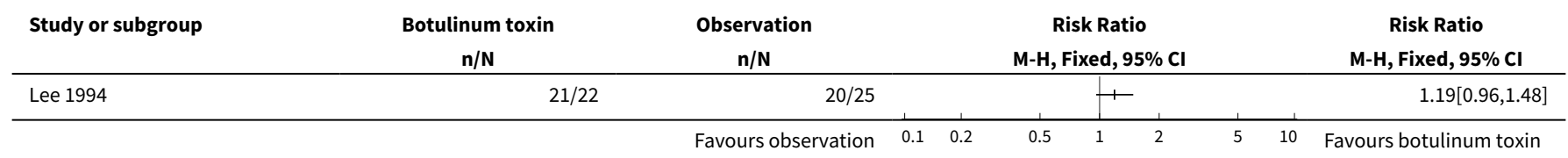

Analysis 2.2. Comparison 2 Botulinum toxin versus observation, Outcome 2 Secondary outcome - classification.

\begin{tabular}{|c|c|c|c|c|c|c|}
\hline \multicolumn{7}{|c|}{ Secondary outcome - classification } \\
\hline Study & Total participants & Success & Satisfactory A & Satisfactory B & Fail & Data \\
\hline Lee 1994 & 47 & 21 (95.5\%) & 3 (12\%) & & $1(4.5 \%)$ & Ordinal \\
\hline
\end{tabular}




\begin{tabular}{llcccc} 
& \multicolumn{3}{c}{ Secondary outcome - classification } \\
Study & Total participants & Success & Satisfactory A & Satisfactory B & Fail \\
\hline $\begin{array}{l}22 \text { (Botulinum toxin) } \\
25 \text { (Observa- } \\
\text { tion/Conservative) }\end{array}$ & $20(80 \%)$ & & \\
\hline
\end{tabular}

Analysis 2.3. Comparison 2 Botulinum toxin versus observation, Outcome 3 Secondary outcome - achievement of binocular single vision.

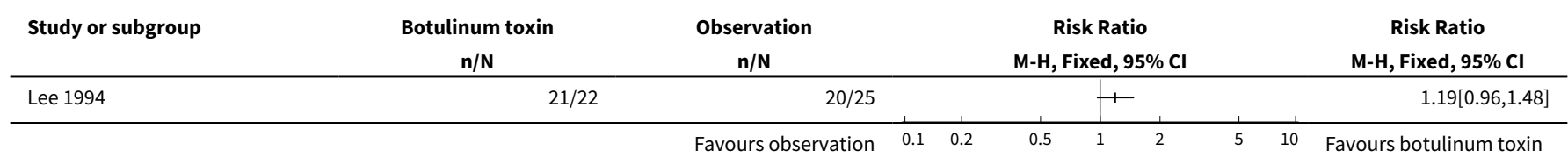

Comparison 3. Surgery with botulinum toxin versus surgery without botulinum toxin

\begin{tabular}{lllll}
\hline Outcome or subgroup title & No. of studies & $\begin{array}{l}\text { No. of partici- } \\
\text { pants }\end{array}$ & Statistical method & Effect size \\
\hline $\begin{array}{l}1 \text { Primary outcome - improved ocular } \\
\text { alignment } \leq 10 \text { PD }\end{array}$ & 1 & & $\begin{array}{l}\text { Risk Ratio (M-H, Fixed, } \\
95 \% \mathrm{Cl})\end{array}$ & $\begin{array}{l}\text { Totals not select- } \\
\text { ed }\end{array}$ \\
\hline
\end{tabular}

Analysis 3.1. Comparison 3 Surgery with botulinum toxin versus surgery without botulinum toxin, Outcome 1 Primary outcome - improved ocular alignment $\leq 10$ PD.

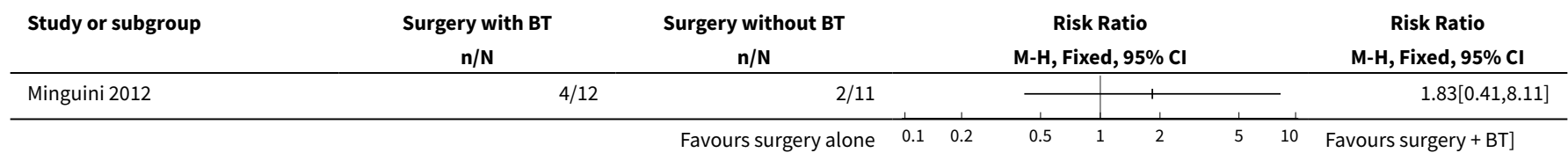

Comparison 4. Botulinum toxin with sodium hyaluronate versus botulinum toxin without sodium hyaluronate

\begin{tabular}{lllll}
\hline Outcome or subgroup title & No. of studies & $\begin{array}{l}\text { No. of partici- } \\
\text { pants }\end{array}$ & Statistical method & Effect size \\
\hline $\begin{array}{l}1 \text { Primary outcome - improved ocular } \\
\text { alignment } \leq 10 \text { PD }\end{array}$ & 1 & & $\begin{array}{l}\text { Risk Ratio (M-H, Fixed, } \\
95 \% \mathrm{Cl})\end{array}$ & $\begin{array}{l}\text { Totals not select- } \\
\text { ed }\end{array}$ \\
\hline
\end{tabular}

Analysis 4.1. Comparison 4 Botulinum toxin with sodium hyaluronate versus botulinum toxin without sodium hyaluronate, Outcome 1 Primary outcome - improved ocular alignment $\leq 10$ PD.

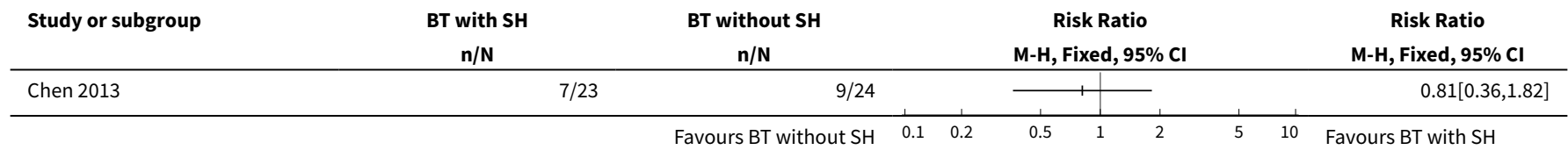




\section{ADDITIONAL TABLES}

Table 1. Botulinum toxin versus observation

\begin{tabular}{llllll}
\hline Study ID & Total participants & Success & $\begin{array}{l}\text { Satisfacto- } \\
\text { ry A }\end{array}$ & $\begin{array}{l}\text { Satisfacto- } \\
\text { ry B }\end{array}$ & Fail \\
\hline Lee 1994 & 22 botulinum toxin & $21(95.5 \%)$ & $3(12 \%)$ & - & $1(4.5 \%)$ \\
& 25 observation/conservative & $20(80 \%)$ & & $2(8 \%)$ \\
& 47 in total & & & \\
\hline
\end{tabular}




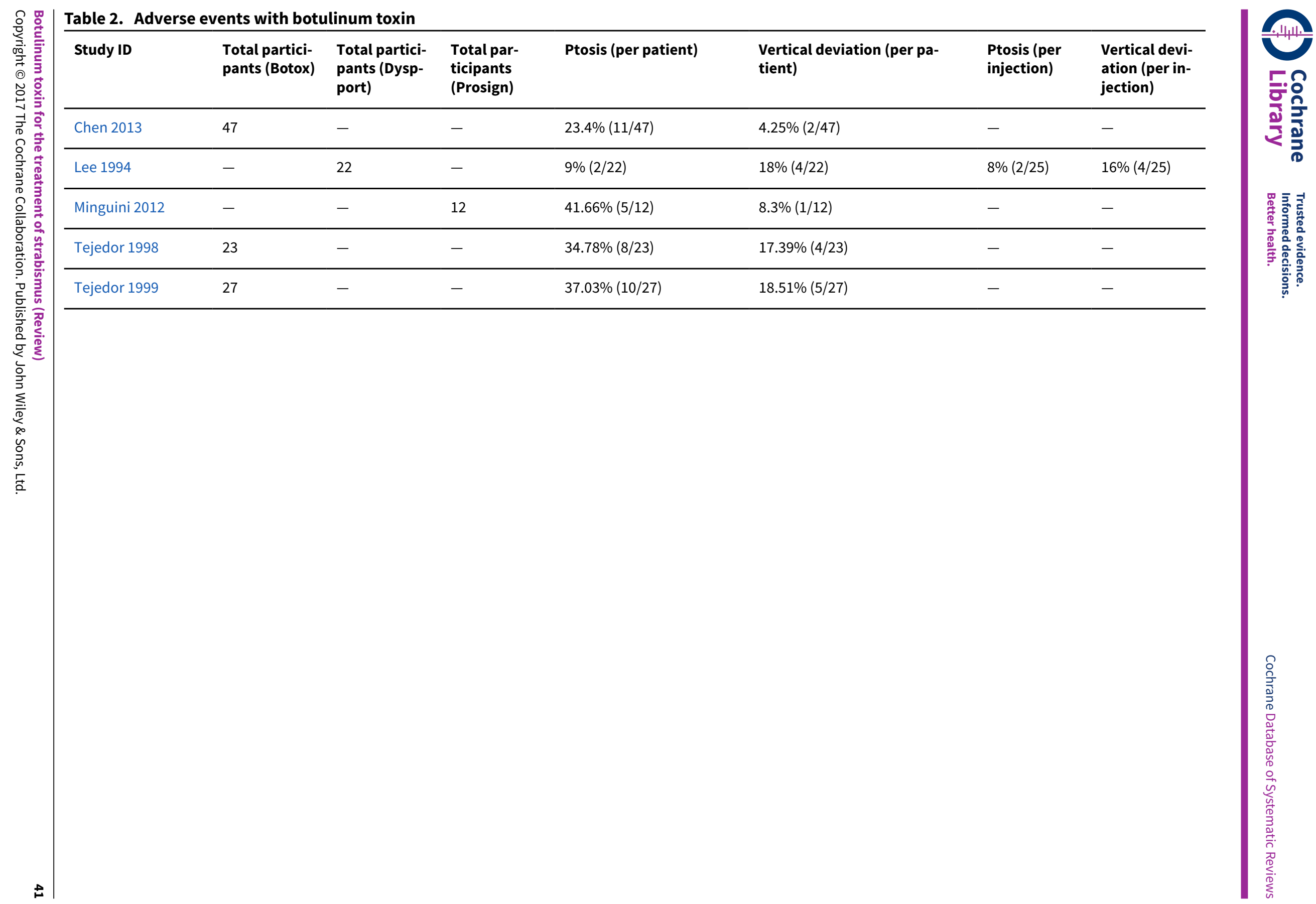




\section{AP PEN DICES}

\section{Appendix 1. CENTRAL search strategy}

\#1 MeSH descriptor Strabismus

\#2 strabism* or squint ${ }^{*}$

\#3 esotropi*

\#4 exotropi*

\#5 hypertropi ${ }^{\star}$

\#6 hypotropi ${ }^{\star}$

\#7 cyclotropi ${ }^{\star}$

\#8 heterophori ${ }^{\star}$

\#9 esophori*

\#10 exophori ${ }^{\star}$

\#11 hyperphori*

\#12 hypophori*

$\# 13$ cyclophori*

\#14 (\#1 OR \#2 OR \#3 OR \#4 OR \#5 OR \#6 OR \#7 OR \#8 OR \#9 OR \#10 OR \#11 OR \#12 OR \#13)

\#15 MeSH descriptor Botulinum Toxins

\#16 botulin* toxin*

\#17 botox*

$\# 18$ dysport*

\#19 MeSH descriptor Clostridium botulinum

\#20 clostridium botulin*

\#21 (\#15 OR \#16 OR \#17 OR \#18 OR \#19 OR \#20)

\#22 (\#14 AND \#21)

\section{Appendix 2. MEDLINE (Ovid) search strategy}

1. randomized controlled trial.pt.

2. (randomized or randomized).ab,ti.

3. placebo.ab,ti.

4. dt.fs.

5. randomly.ab,ti.

6. trial.ab,ti.

7. groups.ab,ti.

8. or/1-7

9. exp animals/

10. exp humans/

11.9 not (9 and 10)

12. 8 not 11

13. exp strabismus/

14. (strabism\$ or squint\$).tw.

15. esotropi\$.tw.

16. exotropi\$.tw.

17. hypertropi\$.tw.

18. hypotropi\$.tw.

19. cyclotropi\$.tw.

20. heterophori\$.tw.

21. esophori\$.tw.

22. exophori\$.tw.

23. hyperphori\$.tw.

24. hypophori\$.tw.

25. cyclophor\$.tw.

26. or/13-25

27. exp botulinum toxins/

28. botulin\$ toxin $\$$.tw.

29. botox\$.tw.

30. dysport\$.tw.

31. exp clostridium botulinum/

32. clostridium botulin\$.tw.

33. or/27-32

Botulinum toxin for the treatment of strabismus (Review) 
34. 26 and 33

35. 12 and 34

The search filter for trials at the beginning of the MEDLINE strategy is from the published paper by Glanville 2006.

\section{Appendix 3. Embase (Ovid) search strategy}

1. exp randomized controlled trial/

2. exp randomization/

3. exp double blind procedure/

4. exp single blind procedure/

5. random\$.tw.

6. or/1-5

7. (animal or animal experiment).sh.

8. human.sh.

9. 7 and 8

10. 7 not 9

11.6 not 10

12. exp clinical trial/

13. (clin\$ adj3 trial\$).tw.

14. ((singl\$ or doubl\$ or trebl\$ or tripl\$) adj3 (blind\$ or mask\$)).tw.

15. exp placebo/

16. placebo\$.tw.

17. random\$.tw.

18. exp experimental design/

19. exp crossover procedure/

20. exp control group/

21. exp latin square design/

22. or $/ 12-21$

23. 22 not 10

24. 23 not 11

25. exp comparative study/

26. exp evaluation/

27. exp prospective study/

28. (control\$ or prospectiv\$ or volunteer\$).tw.

29. or $/ 25-28$

30.29 not 10

31.30 not (11 or 23$)$

32. 11 or 24 or 31

33. exp strabismus/

34. (strabism\$ or squint\$).tw.

35. esotropi\$.tw.

36. exotropi\$.tw.

37. hypertropi\$.tw.

38. hypotropi\$.tw.

39. cyclotropi\$.tw.

40. heterophori\$.tw.

41. esophoris.tw.

42. exophori\$.tw.

43. hyperphori\$.tw.

44. hypophoris.tw.

45. cyclophor\$.tw.

46. or/33-45

47. botulinum toxin/

48. botulin\$ toxin\$.tw.

49. botox\$.tw.

50. dysport\$.tw.

51. Botulinum toxin A/

52. exp clostridium botulinum/

53. clostridium botulin\$.tw.

54. or/47-53

55.46 and 54 
56.32 and 55

\section{Appendix 4. LILACS search strategy}

botulin\$ or botox\$ and strabism\$

\section{Appendix 5. ISRCTN search strategy}

botulinum and strabismus

\section{Appendix 6. ClinicalTrials.gov search strategy}

Strabismus AND (Botox OR Botulinum)

\section{Appendix 7. WHO ICTRP search strategy}

(Condition) Strabismus AND (Intervention) Botox OR Botulinum

WHAT'S NEW

\begin{tabular}{lll}
\hline Date & Event & Description \\
\hline 11 July 2016 & New search has been performed & Issue 3, 2017: electronic searches were updated \\
\hline 11 July 2016 & $\begin{array}{l}\text { New citation required but conclusions } \\
\text { have not changed }\end{array}$ & $\begin{array}{l}\text { Issue 3, 2017: two new trials were included in the review (Chen } \\
\text { 2013; Minguini 2012). Inclusion of GRADE }\end{array}$ \\
\hline
\end{tabular}

\section{H I S T O R Y}

Protocol first published: Issue 2, 2007

Review first published: Issue 2, 2009

\begin{tabular}{lll}
\hline Date & Event & Description \\
\hline 7 December 2011 & $\begin{array}{l}\text { New citation required but conclusions } \\
\text { have not changed }\end{array}$ & $\begin{array}{l}\text { Issue 2, 2012: electronic searches were updated but no new trials } \\
\text { were identified. }\end{array}$ \\
\hline 7 December 2011 & New search has been performed & $\begin{array}{l}\text { Issue 2, 2012: the 'Risk of bias' assessments were updated ac- } \\
\text { cording to new Cochrane methodology. }\end{array}$ \\
\hline 14 October 2008 & Amended & Converted to new review format. \\
\hline
\end{tabular}

\section{CONTRIBUTIONS OF AUTHORS}

FR proposed the review question and co-ordinated the review, organised retrieval of papers and wrote to study authors for additional information.

FR and CN screened search results, screened retrieved papers against inclusion criteria, appraised quality of papers, extracted data from papers, provided additional data about papers, obtained and screened data on unpublished studies, entered data into RevMan 5 (RevMan 2014), provided a methodological, clinical, policy and consumer perspective and wrote the review.

FR and $\mathrm{CN}$ updated the review.

\section{DECLARATIONSOF INTEREST}

FR has no known conflicts of interest.

$\mathrm{CN}$ has no known conflicts of interest. 


\section{SOURCES OF SUPPORT}

\section{Internal sources}

- University of Liverpool, UK.

- Aintree University Hospital NHS Foundation Trust, UK.

\section{External sources}

- National Institute for Health Research (NIHR), UK.

- Richard Wormald, Co-ordinating Editor for the Cochrane Eyes and Vision (CEV) acknowledges financial support for his CEV research sessions from the Department of Health through the award made by the NIHR to Moorfields Eye Hospital NHS Foundation Trust and UCL Institute of Ophthalmology for a Specialist Biomedical Research Centre for Ophthalmology.

- The NIHR also funds the CEV editorial base in London.

The views expressed in this publication are those of the review authors and not necessarily those of the NIHR, the NHS or the Department of Health.

\section{DIFFERENCES BETWEEN PROTOCOLANDREVIEW}

We used the 'Risk of bias' tool to assess the risk of bias of the included studies and the GRADE approach to assess the certainty of the evidence for each outcome. Given the developments in the production and use of botulinum toxin since the original protocol, for interventions in the current review, we added comparisons for the following:

- comparison of botulinum toxin alternatives, i.e. different brands of botulinum toxin compared to each other;

- comparison of botulinum toxin with and without added substances, e.g. sodium hyaluronate, saline.

\section{INDEX TERMS}

\section{Medical Subject Headings (MeSH)}

Abducens Nerve Diseases [ ${ }^{\star}$ drug therapy]; Botulinum Toxins, Type A [adverse effects] [ ${ }^{\star}$ therapeutic use]; Neuromuscular Agents [adverse effects] [ ${ }^{\star}$ therapeutic use]; Randomized Controlled Trials as Topic; Strabismus [ ${ }^{\star}$ drug therapy] [surgery]; Vision, Binocular

\section{MeSH check words}

Adult; Child; Humans 